\title{
Differential prognostic implications of gastric adenocarcinoma based on Lauren's classification: a Surveillance, Epidemiology, and End Results (SEER)-based cohort study
}

\author{
Dehua Tang", Muhan Ni", Hao Zhu", Jun Cao, Lin Zhou, Shanshan Shen, Chunyan Peng, Ying Lv, \\ Guifang Xu, Lei Wang, Xiaoping Zou
}

Department of Gastroenterology, Nanjing Drum Tower Hospital, Affiliated Drum Tower Hospital, Medical School of Nanjing University, Nanjing, China

Contributions: (I) Conception and design: X Zou, L Wang, G Xu; (II) Administrative support: X Zou, Y Lv; (III) Provision of study materials or patients: D Tang, M Ni, H Zhu, J Cao; (IV) Collection and assembly of data: D Tang, J Cao, L Zhou; (V) Data analysis and interpretation: D Tang, J Cao, C Peng, S Shen; (VI) Manuscript writing: All authors; (VII) Final approval of manuscript: All authors.

"These authors contributed equally to this work as co-first authors.

Correspondence to: Xiaoping Zou, MD, PhD; Lei Wang, MD, PhD; Guifang Xu, MD, PhD; Jun Cao, MD, PhD. Department of Gastroenterology, Nanjing Drum Tower Hospital, Affiliated Drum Tower Hospital, Medical School of Nanjing University, 321 Zhongshan Road, Nanjing 210008 , China. Email: zouxp@nju.edu.cn; 867152094@qq.com; 13852293376@163.com; 13601586102@163.com.

Background: Our study aims to analyze the association between Lauren's classification and gastric adenocarcinoma prognosis using comprehensive statistical analyses.

Methods: According to the selection criteria, patients were included from the Surveillance, Epidemiology, and End Results (SEER) database. Univariate and multivariate Cox regression, propensity score matching, and a multivariate competing risk model were used to investigate the association between Lauren's classification and prognosis. Subgroup analysis was used to investigate the role of confounding factors on the association between Lauren types and prognosis.

Results: After exclusion, a total of 20,218 patients from the SEER database were included, with 14,374 intestinal types and 5,844 diffuse types. The univariate Cox regression analysis revealed that the diffuse type had a poorer cancer-specific survival (CSS) rate [hazard ratio (HR), 1.44; 95\% confidence interval (CI), 1.381.50]. After adjusting for confounding variables, the diffuse type also showed a higher risk of cancer-specific death (HR, 1.20; 95\% CI, 1.15-1.20). Sensitivity analysis showed that after propensity score matching, the diffuse type had a poorer CSS rate (HR, 1.23; 95\% CI, 1.10-1.36), and the competing risk model further validated these results [subdistribution HR (SHR), 1.32; 95\% CI, 1.23-1.41]. Moreover, subgroup analysis demonstrated stable results in the subgroups, except for patients with T1 stage (HR, 1.06; 95\% CI, 0.87-1.28) and a tumor size $<2 \mathrm{~cm}$ (HR, 1.00; 95\% CI, 0.83-1.21).

Conclusions: Diffuse-type gastric adenocarcinoma had an overall poorer prognosis compared to the intestinal type. However, in patients with T1 stage and tumor size $<2 \mathrm{~cm}$, the diffuse type had a comparable survival rate with the intestinal type.

Keywords: Gastric adenocarcinoma; Lauren's classification; Surveillance, Epidemiology, and End Results (SEER); survival

Submitted Dec 12, 2020. Accepted for publication Feb 02, 2021.

doi: $10.21037 / \mathrm{atm}-20-7953$

View this article at: http://dx.doi.org/10.21037/atm-20-7953 


\section{Introduction}

Gastric adenocarcinoma is the main type of gastric cancer (GC), accounting for approximately $95 \%$ of all cases (1). Although numerous novel therapies have been developed in recent decades, surgical resection remains the only curative therapy for this malignancy (2). However, due to a lack of effective methodologies to diagnose this malignancy at an early stage, most patients are diagnosed at advanced stages and do not meet surgical resection indications (3). Hence, most gastric adenocarcinoma patients' prognosis remains poor, with a 5 -year survival rate of less than $25 \%$ (2).

Lauren's classification is the most commonly used histological subtype criteria for predicting prognosis and establishing a treatment strategy in gastric adenocarcinoma (4-7). Lauren's classification divides gastric adenocarcinoma into two histological subtypes: an intestinal type and a diffuse type (8). Previous reports have shown that diffusetype gastric adenocarcinoma exhibits a comparable strong association with Helicobacter pylori (H. pylori) infection compared with intestinal type via different mechanisms (9). Intestinal-type lesions derive from premalignant lesions through an initial $H$. pylori-induced chronic gastritis and subsequent atrophic and metaplastic gastritis (10). Diffusetype lesions also originate from $\mathrm{H}$. pylori-induced chronic inflammation with overpassing multiple steps including atrophic gastritis and intestinal metaplasia $(11,12)$. According to the British Society of Gastroenterology's latest guidelines, complete (R0) endoscopic resection is recommended to patients with intestinal-type intramucosal gastric adenocarcinoma but is not suitable for those with the diffuse type (13). However, recent studies have shown significant variations in patients' clinical outcomes with the same histological subtype. For instance, numerous studies have demonstrated that diffuse-type lesions are associated with younger age, a higher risk of lymph node metastasis (LNM), and a worse prognosis than intestinal-type lesions (14-18). However, several recent studies reported that diffuse-type gastric adenocarcinoma, such as signet ring cell (SRC), showed a similar or even better prognosis than other histologic subtypes at an early stage (19-22). Although the sample sizes of these studies were relatively small and, stagestratified analyses were lacking. Also, only a few studies considered the interaction between confounding factors and Lauren's classification. Therefore, more studies are needed to confirm Lauren's classification's clinical role and provide adequate prognostic information to facilitate personalized medicine.

In this study, we investigated the association between Lauren's classification and cause-specific prognosis. Multivariate regression was performed to adjust confounding factors to reveal the independent association between Lauren's classification and cause-specific prognosis. Subgroup and sensitivity analyses were performed to validate the independent association. This study may provide evidence for therapeutic decision-making and follow-up strategies for different histologic types of gastric adenocarcinoma. We present the following article in accordance with the STROBE reporting checklist (available at http://dx.doi.org/10.21037/ atm-20-7953).

\section{Methods}

\section{Patients}

This is a retrospective cohort study. All patients with gastric adenocarcinoma were retrieved from the Surveillance, Epidemiology, and End Results (SEER) database using SEER*Stat software (version 8.6.1; www.seer.cancer.gov). Informed consent or ethical approval was not required since the SEER database only contains de-identified data and is publically available. The study was conducted in accordance with the Declaration of Helsinki (as revised in 2013).

The International Classification of Diseases for Oncology (ICD-O, third edition) was used to identify intestinal- or diffuse-type gastric adenocarcinoma patients. Intestinal-type gastric adenocarcinoma includes carcinoma [not otherwise specified (NOS); M8010], adenocarcinoma (NOS; M8140), tubular (M8211), and intestinal-type (M8144). Meanwhile, the diffuse type includes SRC (M8490), diffuse carcinoma (M8145), and linitis plastica (M8142) (23).

A total of 78,303 patients diagnosed with GC between 2004 and 2015 were included in this study since data before 2004 lacked detailed information concerning cancer staging. The exclusion criteria were as follows: (I) GC was not the first diagnosed primary tumor $(\mathrm{N}=14,344)$; (II) GC with unknown surgery status, unknown histological information, or no tumor $(\mathrm{N}=34,579)$; (III) GC with other pathological types (not intestinal or diffuse type, $\mathrm{N}=7,572$ ); (IV) gastric adenocarcinoma with no complete dates of follow-up $(\mathrm{N}=1,142)$; and $(\mathrm{V})$ gastric adenocarcinoma with an unknown reason for death $(\mathrm{N}=448)$. After exclusion, 20,218 patients with gastric adenocarcinoma were included for analysis. 


\section{Variables and outcomes}

The clinicopathological variables extracted from the SEER database included age, sex, race, year of diagnosis, primary site, pathology grade, tumor $(\mathrm{T})$ stage, node $(\mathrm{N})$ stage, metastasis $(M)$ stage, regional nodes examined, regional nodes positive, operation, radiation, chemotherapy, insurance, and marital status. Age was recorded as a continuous variable in the univariable and multivariable analyses, and as a binary variable (classified into two groups: $<70$ years and $\geq 70$ years) in subgroups and interactions analyses. Sex was recorded as male or female. The year of diagnosis was classified into three groups (2004-2007, 2008-2011, 2012-2015) according to the univariable analysis coefficient. The primary site was classified into nine different sites: cardia, fundus, lesser curve, greater curve, gastric body, antrum, pylorus, NOS, and overlapping lesion in the univariable and multivariable analyses, and five sites according to the mucosal origin, including cardia, oxyntic mucosa, antral mucosa, stomach NOS and overlapping lesions in subgroups, interactions and sensitivity analyses. The pathological grade was recorded as moderately or welldifferentiated, poorly differentiated or undifferentiated, and unknown. T stage was recorded as T1 (mucosa or submucosa), T2a (muscularis propria), T2b (subserosa), T2 NOS (muscularis propria or subserosa, NOS), T3 (penetrates serosa), T4 (adjacent structures), and TX (unknown). $\mathrm{N}$ stage was recorded as $\mathrm{N} 0$ (no lymph nodes positive), N1 (1-6 nodes positive), N2 (7-15 nodes positive), N3 (>15 nodes positive), and NX (unknown). M stage was recorded as M0 (no distant metastasis) and M1 (distant metastasis). The operation was recorded as an endoscopy and surgery. Radiation therapy and chemotherapy were recorded as none/unknown and yes, respectively. Tumor size was classified into five groups according to the diameter: $\mathrm{T} \leq 2 \mathrm{~cm}, \mathrm{~T} \leq 3 \mathrm{~cm}, \mathrm{~T} \leq 5 \mathrm{~cm}, \mathrm{~T}>5 \mathrm{~cm}$, and unknown. The race was recorded as White, Asian or Pacific Islander, Black, American Indian/Alaska Native, and unknown. Insurance was recorded as insured, Medicaid, uninsured, and unknown. Marital status was recorded as married, divorced or separated, widowed, single (never married), unmarried or domestic partner, and unknown. The primary outcome was cancer-specific survival (CSS). Survival time was defined as the time from diagnosis to the date of death or the date of last contact (or November 2016). CSS referred to death caused by gastric adenocarcinoma. In the competing risk model, mortality was recorded as death related to gastric adenocarcinoma and death related to other causes. Patients who were still alive at the date of the last follow-up were censored.

\section{Statistical analyses}

For descriptive statistics, categorical variables were presented as frequencies and percentages, while continuous variables were presented with Gaussian distribution as means and standard deviations and as medians and interquartile ranges with non-normal distribution. Different patient groups were compared with the chi-square test for categorical variables, the Student's $t$-test for continuous variables with Gaussian distribution, and the nonparametric Kruskal-Wallis rank-sum test for continuous variables with non-normally distributed data or ordinal categorical variables. CSS curves were produced using the KaplanMeier method, and a log-rank test was used for comparison. Univariable Cox regression was performed to investigate the effect size of potential risk factors for CSS, with results presented as a hazard ratio (HR) with $95 \%$ confidence interval (CI). Multivariate Cox regression was further conducted to investigate Lauren's classification and CSS's association with two models adjusting for confounding variables. The model I confounders was selected based on their associations with the outcomes of a change in effect estimate of more than $10 \%$ (data not shown). All baseline parameters and clinical characteristics were included for adjustment as confounders in model II.

Furthermore, a sensitivity analysis was performed to validate Lauren's classification and CSS's association using two models. Propensity score matching (PSM) was performed to match the potential confounders selected in the multivariate Cox regression model. According to histology in a multivariate logistic regression model, propensity scores were calculated for every patient with gastric adenocarcinoma. Diffuse-type patients were matched with intestinal-type patients at a ratio of 1:1. Further univariable and multivariate Cox regression analyses, Kaplan-Meier curves, and log-rank tests were conducted among the new cohort with well-balanced clinical characteristics.

Additionally, for the competing risk model analysis, death unrelated to gastric adenocarcinoma was simultaneously modeled as a competing risk. Patients who were still alive were censored. Gray's test was applied to compare the two histologic types' CSS, and results were presented by subdistribution HRs (SHRs) and 95\% CIs. Interaction 


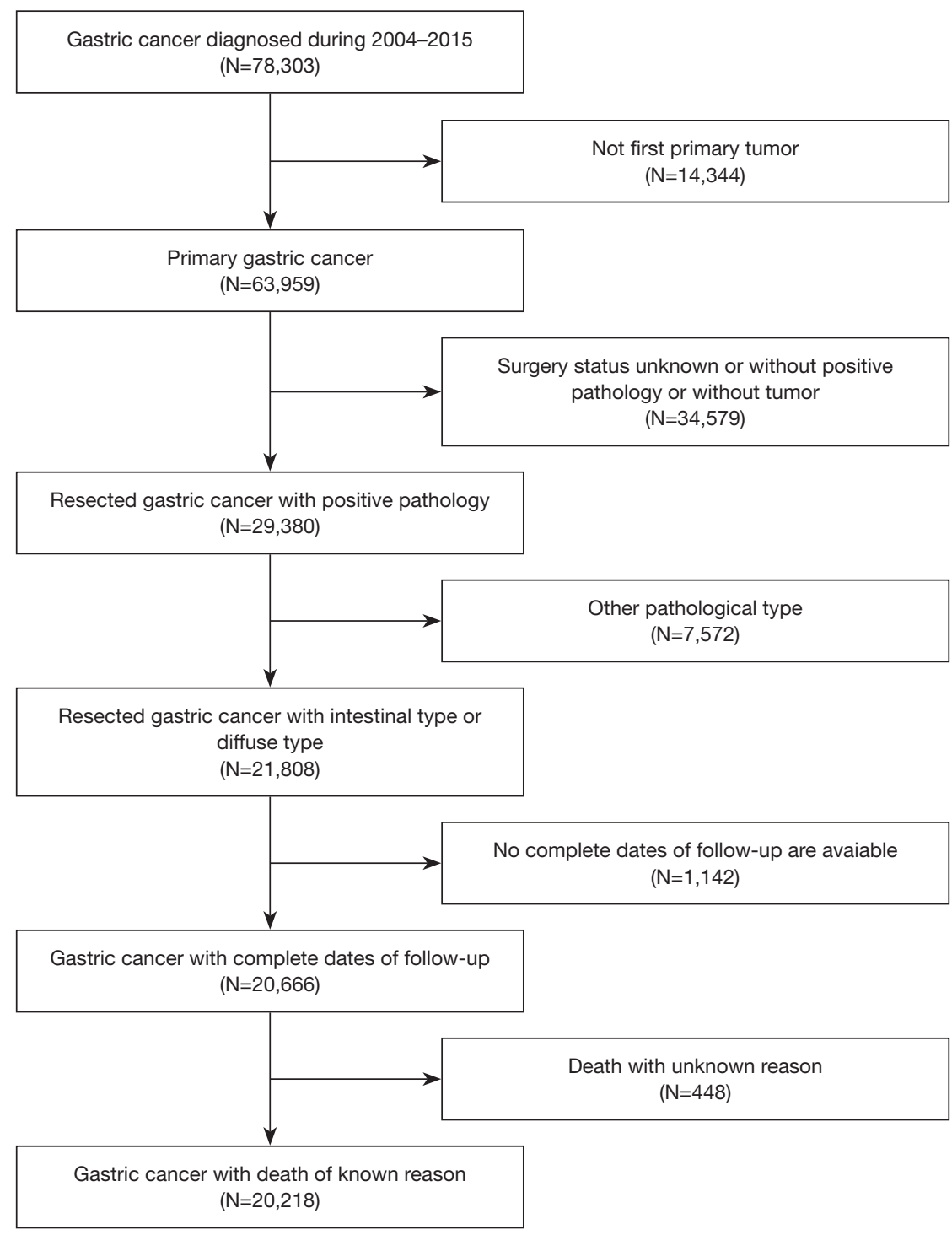

Figure 1 Flow chart of study participants

and stratified analyses were also conducted according to the risk factors selected from model I described above. To minimize selection bias, we included as many cases as possible, including cases containing missing data in nongrouped variables. The missing data in each item were listed and calculated in the regression formula as a separate group. Based on the univariable Cox regression results, we combined the missing data groups to groups with similar effect coefficients when performing survival and subgroup analyses. All the analyses were performed using EmpowerStats (https://www.empowerstats.com) and R statistical software (version 4.0.2, The R Foundation). A two-sided $\mathrm{P}<0.05$ was considered statistically significant.

\section{Results}

\section{Clinical characteristics of patients with gastric adenocarcinoma}

After exclusion, a total 20,218 patients were finally included in this study, consisting of 14,374 intestinal-type patients (71.1\%) and 5,844 diffuse-type patients (28.9\%) (Figure 1). The clinical characteristics of patients with these two histologic types are outlined in Table 1. Results showed that intestinal-type patients had a better survival rate than diffusetype patients, with a median survival time of 27 months (interquartile range, 12-62 months) for the intestinal type and 20 months (interquartile range, 9-48 months) 
Table 1 Baseline characteristics of the participants

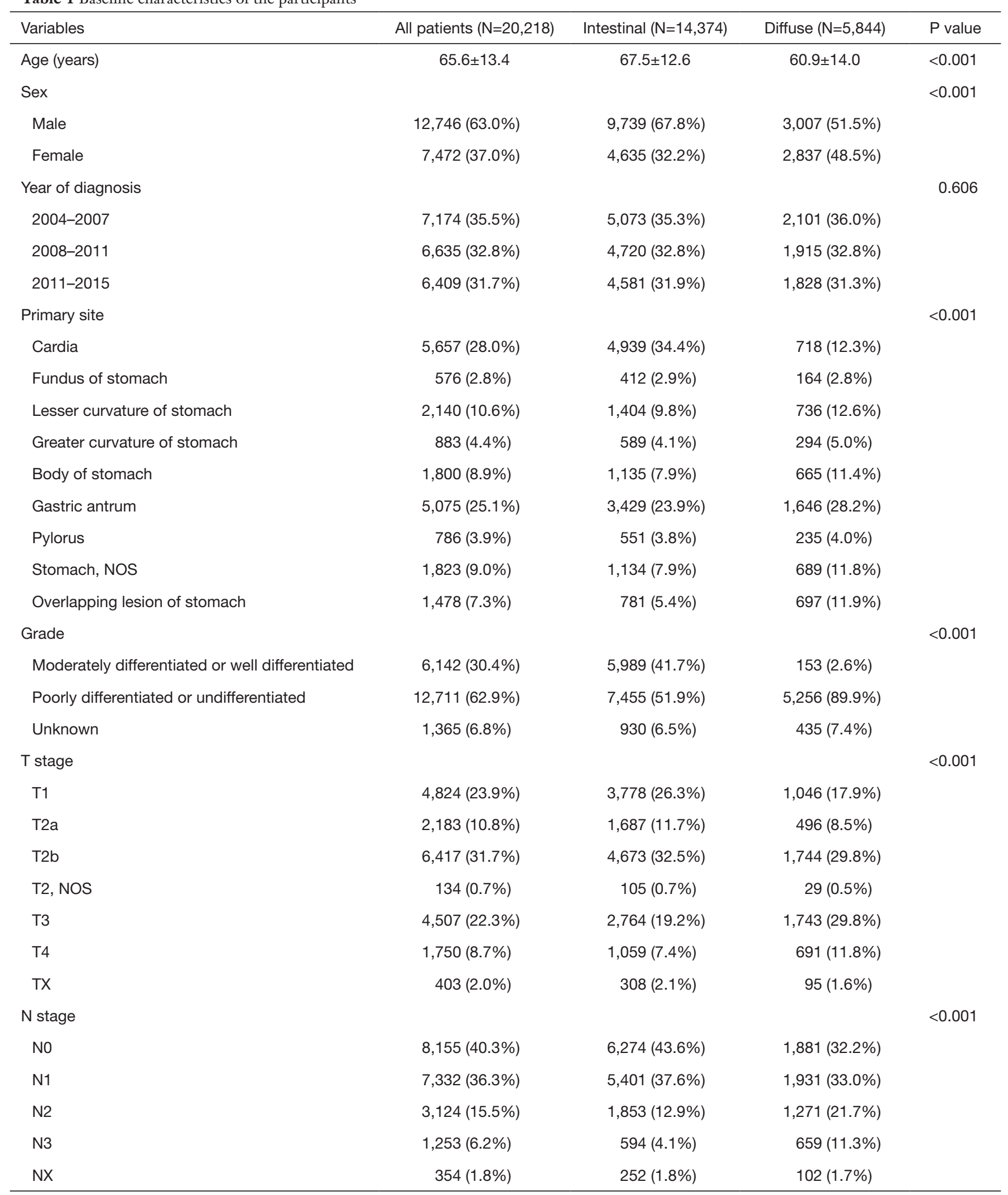

Table 1 (continued) 
Table 1 (continued)

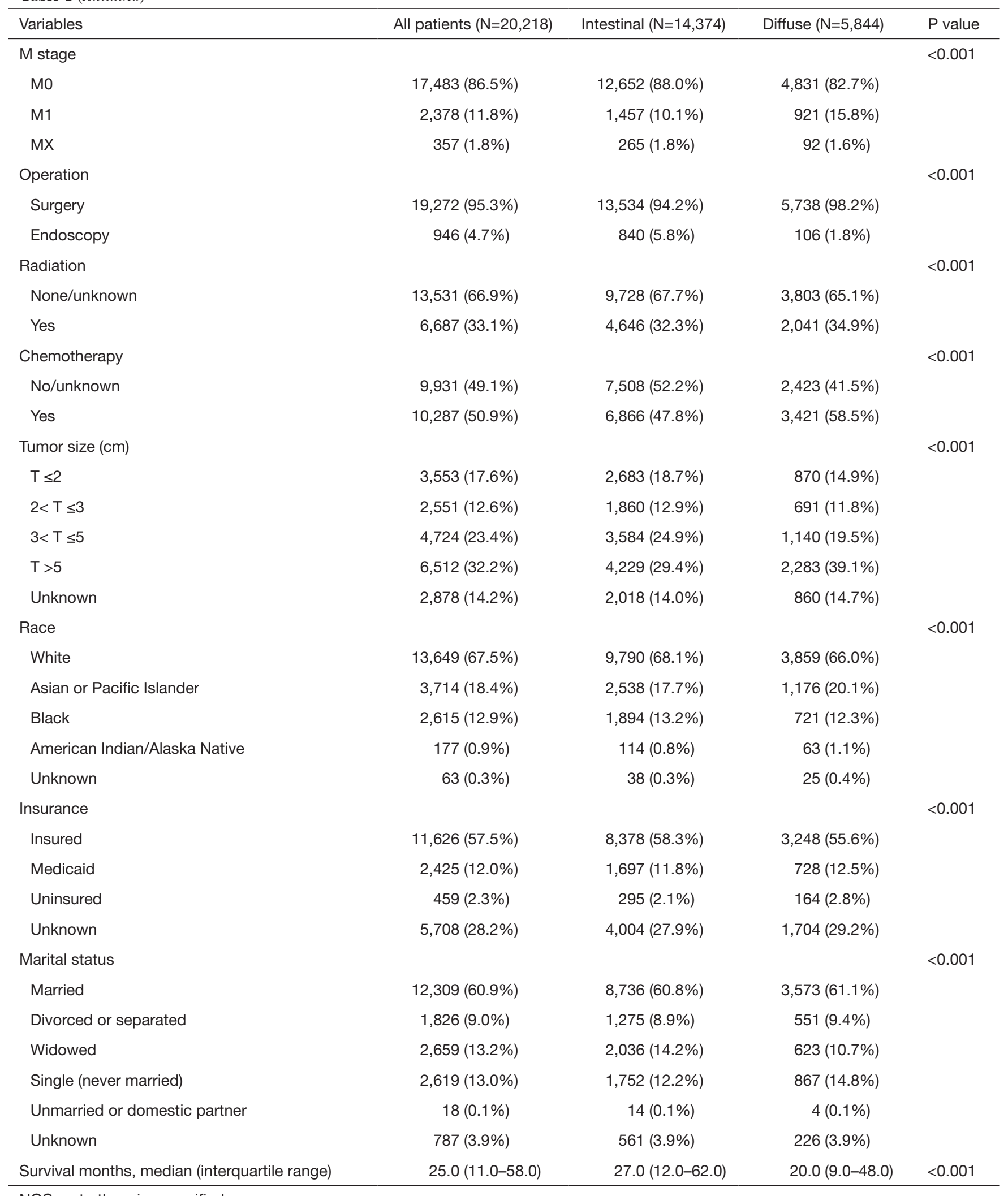

NOS, not otherwise specified. 


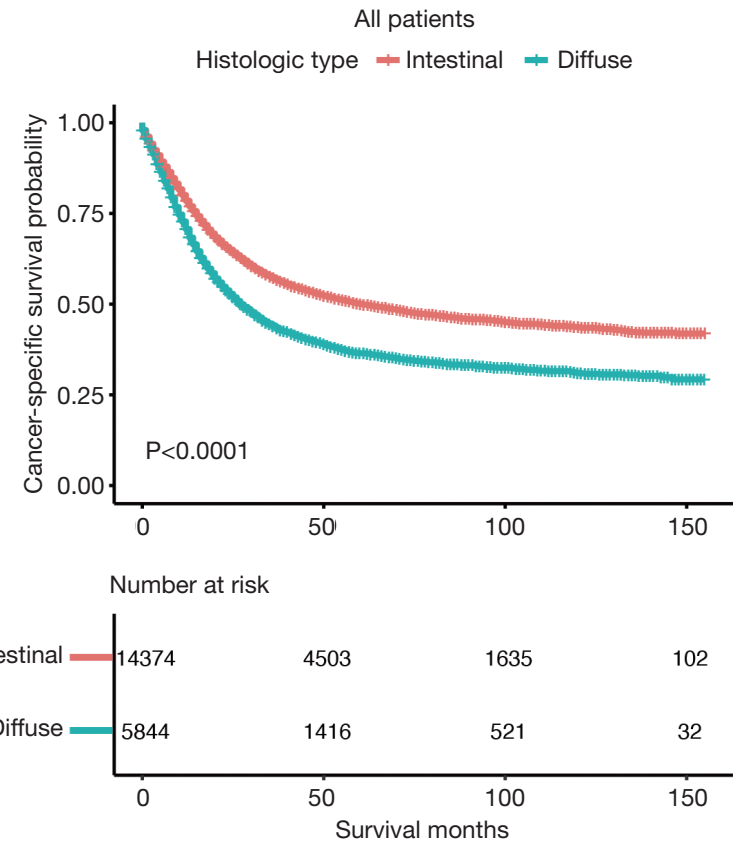

Figure 2 Kaplan-Meier analysis of cancer-specific survival based on Lauren's classification.

for the diffuse type. The results also showed that patients with diffuse-type were younger females, and lesions were mostly located in gastric antrum with a larger size and poorer differentiation grade than the intestinal type. Also, patients with diffuse-type exhibited a lower proportion of T1 stage, N0 stage, and M0 stage lesions and a higher proportion of radiation therapy and chemotherapy than intestinal type patients.

\section{CSS in intestinal and diffuse types}

The CSS of gastric adenocarcinoma was initially compared using Kaplan-Meier curves. The results showed that in the total cohort, intestinal-type gastric adenocarcinoma had a significantly higher CSS rate than the diffuse type (Figure 2, $\mathrm{P}<0.0001$ ). To identify the prognostic factors and analyze the potential risk factors for poor CSS of gastric adenocarcinoma, univariable and multivariate Cox regression analyses were carried out. According to the univariate Cox analysis, age at diagnosis $(\mathrm{P}<0.0001)$, sex $(\mathrm{P}=0.0248)$, year of diagnosis $(\mathrm{P}<0.0001)$, primary site $(\mathrm{P}<0.0001)$, grade of differentiation $(\mathrm{P}<0.0001)$, histologic type $(\mathrm{P}<0.0001)$, $\mathrm{T}$ stage $(\mathrm{P}<0.0001), \mathrm{N}$ stage $(\mathrm{P}<0.0001)$, $M$ stage $(\mathrm{P}<0.0001)$, operation $(\mathrm{P}<0.0001)$, chemotherapy $(\mathrm{P}<0.0001)$, tumor size $(\mathrm{P}<0.0001)$, race $(\mathrm{P}<0.0001)$, insurance $(\mathrm{P}<0.0001)$, and marital status $(\mathrm{P}<0.0001)$ were significantly associated with CSS (Table 2).

The univariate Cox regression analysis demonstrated that diffuse-type gastric adenocarcinoma had a poorer CSS rate than intestinal-type gastric adenocarcinoma (Table 3; HR, 1.44; 95\% CI, 1.38-1.50, $\mathrm{P}<0.001)$. After adjusting for confounding variables including the age of diagnosis, primary site, the grade of differentiation, $\mathrm{T}$ stage, $\mathrm{N}$ stage, $M$ stage, and tumor size (model I), the diffuse-type group still exhibited a significantly higher risk of cancerspecific death than the intestinal-type group (HR, 1.19; 95\% CI, 1.14-1.25, $\mathrm{P}<0.001)$. Notably, after adjusting all the potential confounding variables (model II), the diffusetype group also showed a significantly higher risk of cancerspecific death than the intestinal-type group (HR, 1.20; 95\% CI, 1.15-1.20, $\mathrm{P}<0.001)$.

\section{Comparison of CSS in intestinal and diffuse types in subgroups}

We further performed a subgroup analysis to estimate the role of potential confounding factors on the association between Lauren's classification and CSS rate. As shown in Figure 3, the subgroup analysis revealed a highly consistent pattern. In the T1-stage subgroup, the effect of the diffusetype group was similar to that of the intestinal-type group (HR, 1.06; 95\% CI, 0.87-1.28), while in the T2-TX subgroup, the diffuse-type group showed a higher risk of cancer-specific death than the intestinal-type group (HR, 1.24; $95 \%$ CI, 1.19-1.31; P for interaction $=0.107$ ). In the subgroup with tumor-size $<2 \mathrm{~cm}$, the diffuse-type group showed a comparable risk of cancer-specific death with the intestinal-type group (HR, 1.00; 95\% CI, 0.83-1.21), but in the subgroup with tumor-size $>2 \mathrm{~cm}$, the diffuse-type group exhibited a poorer CSS (HR, 1.22; 95\% CI, 1.16-1.28; P for interaction $=0.035$ ). In all other subgroups, including the age of diagnosis, sex, $\mathrm{N}$ stage, $\mathrm{M}$ stage, the grade of differentiation, year of diagnosis and primary sites, Lauren's classification and CSS's association were consistent.

\section{Survival analysis of patients with intestinal-type and diffuse-type gastric adenocarcinoma}

To further investigate the association between Lauren's classification and CSS, we first compared the Kaplan-Meier curves of the intestinal and diffuse types in the subgroups based on the subgroups analysis results. For gastric adenocarcinoma with a different differentiation status, 
Table 2 Univariable Cox regression analysis for cancer-specific survival in patients with gastric cancer

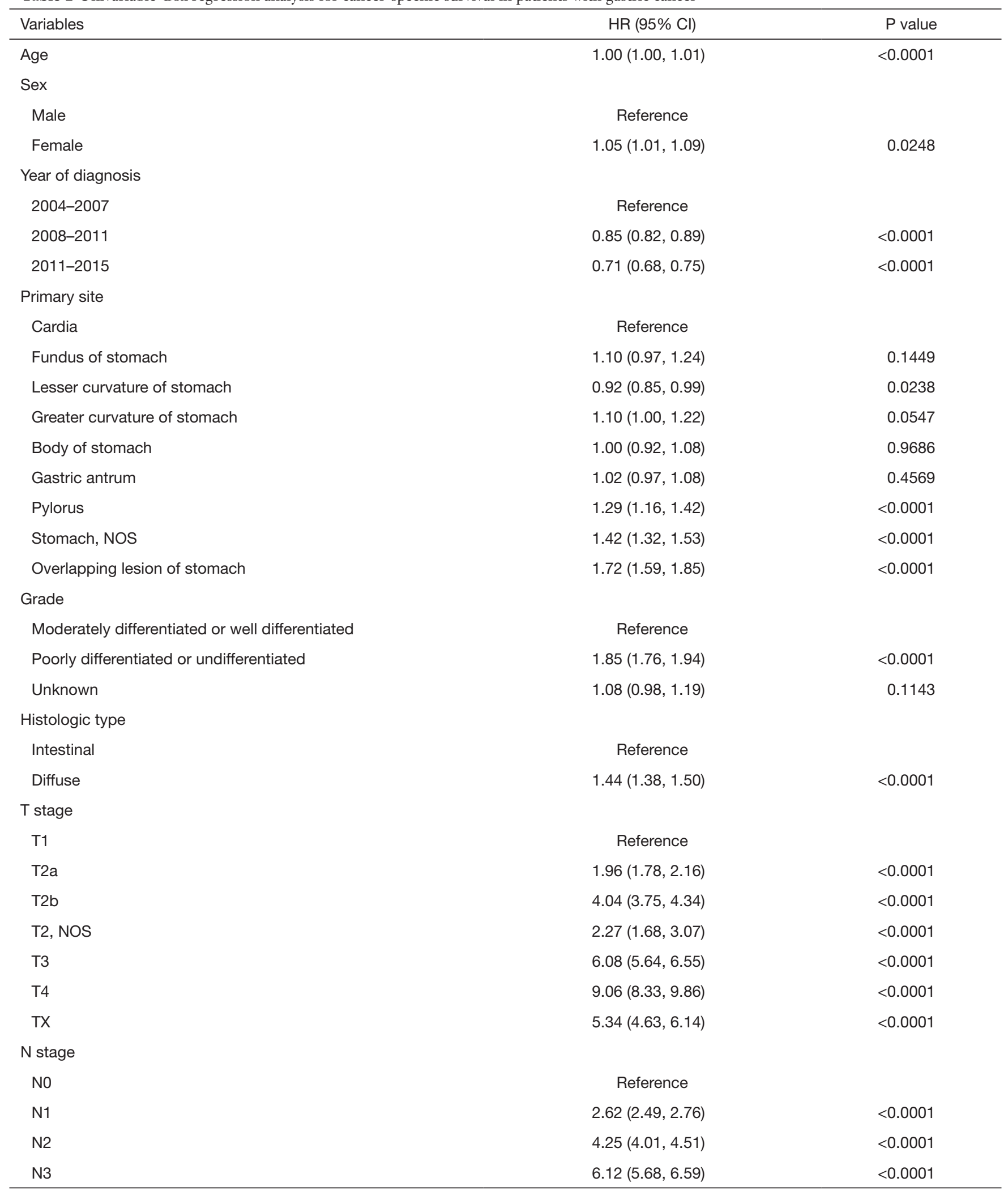

Table 2 (continued) 
Table 2 (continued)

\begin{tabular}{|c|c|c|}
\hline Variables & $\mathrm{HR}(95 \% \mathrm{Cl})$ & $P$ value \\
\hline \multicolumn{3}{|l|}{ M stage } \\
\hline MO & Reference & \\
\hline M1 & $3.80(3.62,4.00)$ & $<0.0001$ \\
\hline Surgery & Reference & \\
\hline Endoscopy & $0.77(0.69,0.85)$ & $<0.0001$ \\
\hline \multicolumn{3}{|l|}{ Radiation } \\
\hline None/unknown & Reference & \\
\hline No/unknown & Reference & \\
\hline Yes & $1.20(1.16,1.25)$ & $<0.0001$ \\
\hline \multicolumn{3}{|l|}{ Tumor size (cm) } \\
\hline $\mathrm{T} \leq 2$ & Reference & \\
\hline $2<\mathrm{T} \leq 3$ & $1.96(1.79,2.14)$ & $<0.0001$ \\
\hline $3<\mathrm{T} \leq 5$ & $2.80(2.59,3.03)$ & $<0.0001$ \\
\hline $\mathrm{T}>5$ & $3.90(3.62,4.20)$ & $<0.0001$ \\
\hline Unknown & $2.68(2.46,2.92)$ & $<0.0001$ \\
\hline Unknown & $0.14(0.06,0.33)$ & $<0.0001$ \\
\hline \multicolumn{3}{|l|}{ Insurance } \\
\hline Insured & Reference & \\
\hline Medicaid & $1.14(1.07,1.22)$ & $<0.0001$ \\
\hline Uninsured & $1.23(1.07,1.40)$ & 0.0034 \\
\hline Unknown & $1.26(1.20,1.31)$ & $<0.0001$ \\
\hline \multicolumn{3}{|l|}{ Marital status } \\
\hline Married & Reference & \\
\hline Divorced or separated & $1.11(1.03,1.19)$ & 0.0041 \\
\hline Widowed & $1.26(1.19,1.34)$ & $<0.0001$ \\
\hline Single (never married) & $1.14(1.08,1.21)$ & $<0.0001$ \\
\hline Unmarried or domestic partner & $0.79(0.35,1.75)$ & 0.5540 \\
\hline Unknown & $0.92(0.82,1.02)$ & 0.1272 \\
\hline
\end{tabular}

NOS, not otherwise specified; HR, hazard ratio; Cl, confidence interval. 
Table 3 Multivariable Cox regression models evaluating the association between Lauren's classification and cancer-specific survival

\begin{tabular}{|c|c|c|c|c|c|c|}
\hline $\begin{array}{l}\text { Lauren's } \\
\text { classification }\end{array}$ & \multicolumn{2}{|c|}{ Crude } & \multicolumn{2}{|c|}{ Model I } & \multicolumn{2}{|c|}{ Model II } \\
\hline Intestinal & Reference & & Reference & & Reference & \\
\hline Diffuse & $1.44(1.38,1.50)$ & $<0.001$ & $1.19(1.14,1.25)$ & $<0.001$ & $1.20(1.15,1.26)$ & $<0.001$ \\
\hline
\end{tabular}

Adjustment I: age; primary site; grade; T stage; N stage; M stage; tumor size. Adjustment II: age; sex; year; primary site; grade; T stage; N stage; M stage; operation; chemotherapy; tumor size; race; insurance; marital status. HR, hazard ratio; $\mathrm{Cl}$, confidence interval.

the CSS rate was also significantly higher in intestinaltype gastric adenocarcinoma (Figure $4 A, B$ ). In the T1 stage gastric adenocarcinoma, the diffuse type showed a comparable CSS rate compared with the intestinal type, while in the T2-TX stage, the intestinal type exhibited a higher CSS rate than the diffuse type (Figure 4C,D). In gastric adenocarcinoma with different $M$ stages, the intestinal type also showed a higher CSS rate than the diffuse type (Figure 4E,F). In gastric adenocarcinoma with size $<2 \mathrm{~cm}$, the diffuse type showed a comparable CSS rate compared with the intestinal type, while in patients with size $>2 \mathrm{~cm}$, the intestinal type showed a higher CSS rate than the diffuse type (Figure 4G,H). In gastric adenocarcinoma with different primary sites, the intestinal type showed a significantly higher CSS rate than the diffuse type in each site (Figure S1).

\section{Sensitivity analysis}

We matched 1,311 intestinal-type patients with 1,311 diffuse-type patients with 1:1 PSM based on the significant confounding variables mentioned in model I. As shown in Table S1, the clinical characteristics were comparable and balanced between the intestinal and diffuse types, apart from sex and radiation condition. We performed KaplanMeier curve analysis after PSM and found a positive association between diffuse-type gastric adenocarcinoma and a poorer CSS rate (Figure S2; P=0.00014). Univariable Cox regression analysis was performed to investigate the association between Lauren's classification and CSS in the matched cohort. In the univariable analysis, diffusetype gastric adenocarcinoma had a poorer CSS rate than intestinal-type gastric adenocarcinoma (Table S2; HR, 1.23; 95\% CI, 1.10-1.36). Notably, the risk effect remained stable after adjusting for sex with multivariable analysis (Table S3; model I; HR, 1.22; 95\% CI, 1.10-1.36) or adjusting for both sex and radiation in model II (HR, 1.22; 95\% CI, 1.10-1.36). The competing risk model further validated that the diffuse type was associated with a worse risk of death than the intestinal type, and the result was statistically significant (Table S4; SHR, 1.32; 95\% CI, 1.23-1.41).

We also classified the primary site into five categories according to the mucosal origin, including cardia, oxyntic mucosa, antral mucosa, stomach NOS and overlapping lesions to perform further analysis. The results of univariable Cox regression analysis showed that lesions from cardia, oxyntic mucosa, and antral mucosal showed a marginally different impact on CSS of gastric adenocarcinoma (Table S5, cardia, HR, reference; oxyntic mucosa, HR, 0.99, 95\% CI, 0.94-1.05; antral mucosa, HR, $1.05,95 \%$ CI, 1.00-1.11). The results of multivariable Cox regression models showed that the association of Lauren's classification and CSS was stable (Table S6, HR, 1.19; 95\% CI, 1.13-1.24, $\mathrm{P}<0.001$ ) with adjusting the age of diagnosis, primary site (five sites), grade of differentiation, $\mathrm{T}$ stage, $\mathrm{N}$ stage, $\mathrm{M}$ stage and tumor size (model III), which was comparable to nine sites (HR, 1.19; 95\% CI, 1.14-1.25, $\mathrm{P}<0.001)$. After adjusting all the potential confounding variables (five sites, model IV), the diffuse-type group also showed a significantly higher risk of cancer-specific death than the intestinal-type group (HR, 1.20; 95\% CI, 1.15-1.26, $\mathrm{P}<0.001)$. Besides, the subgroup analysis revealed a highly consistent pattern with these results. In the subgroups with different mucosal origins, the diffusetype group showed more inferior CSS (Figure 3, HR >1.00; $\mathrm{P}$ for interaction $=0.299$ ) compared with the intestinal type. These results demonstrated that mucosal origin had marginal effects on the association between Lauren's classification and CSS of gastric adenocarcinoma.

\section{Discussion}

In the present study, we comprehensively analyzed the difference in prognosis between diffuse-type and intestinaltype gastric adenocarcinoma. This study contained the largest number of patients with gastric adenocarcinoma 


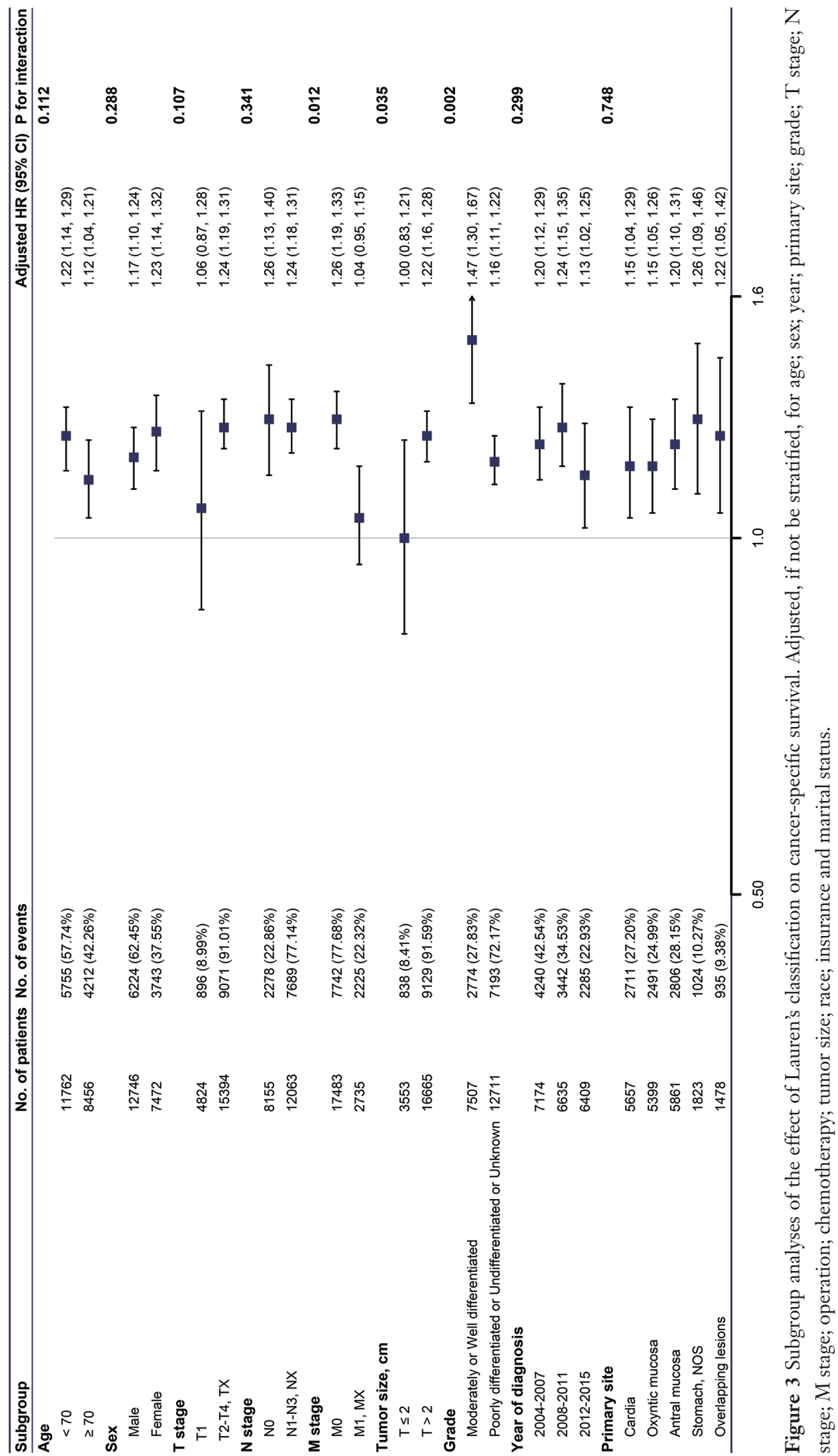


A
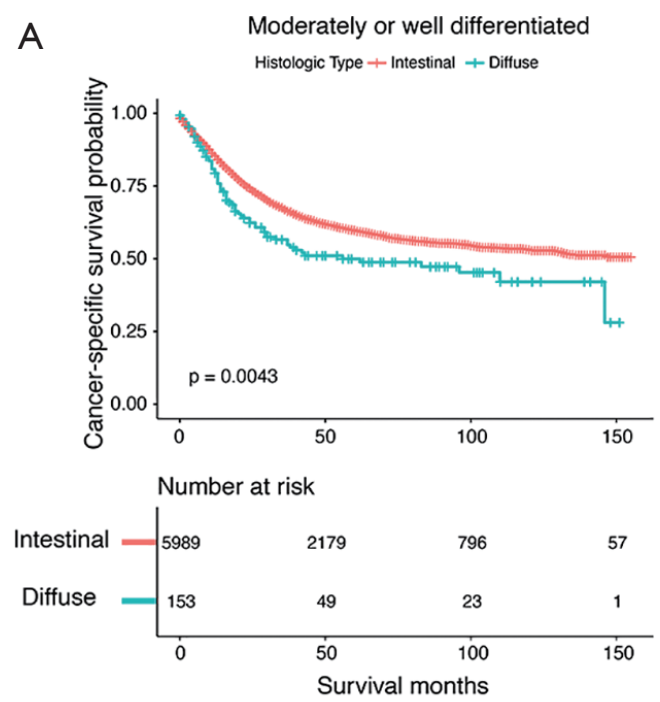

C

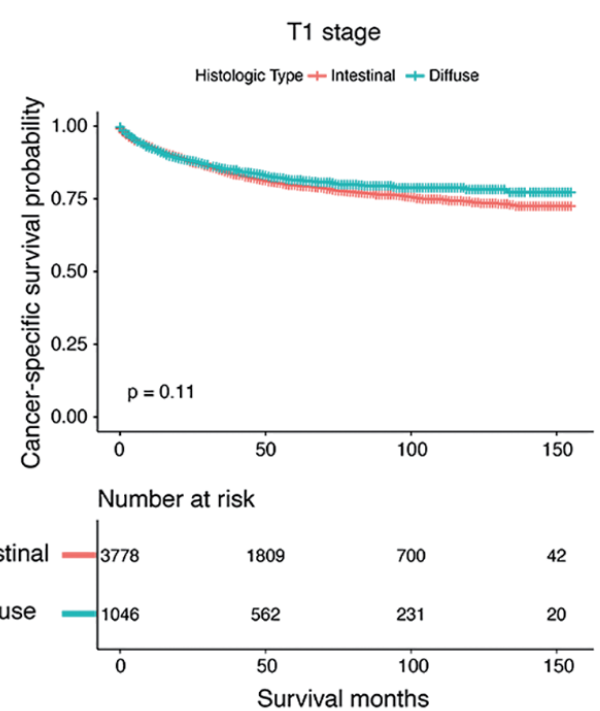

$E$

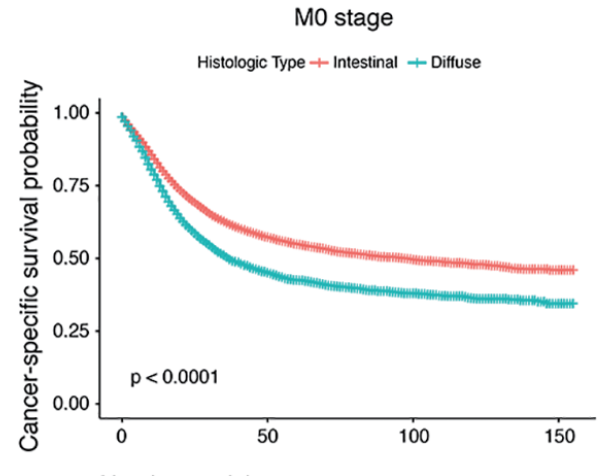

B
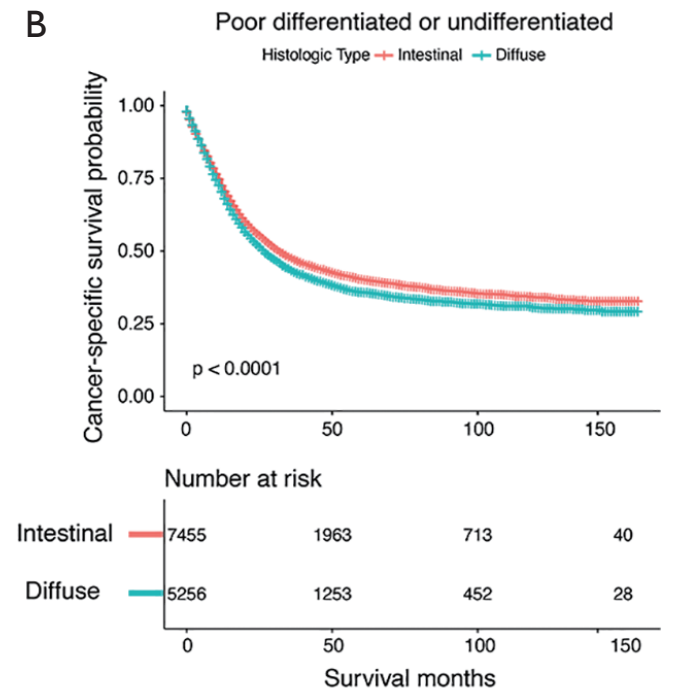

D

T2-TX stage
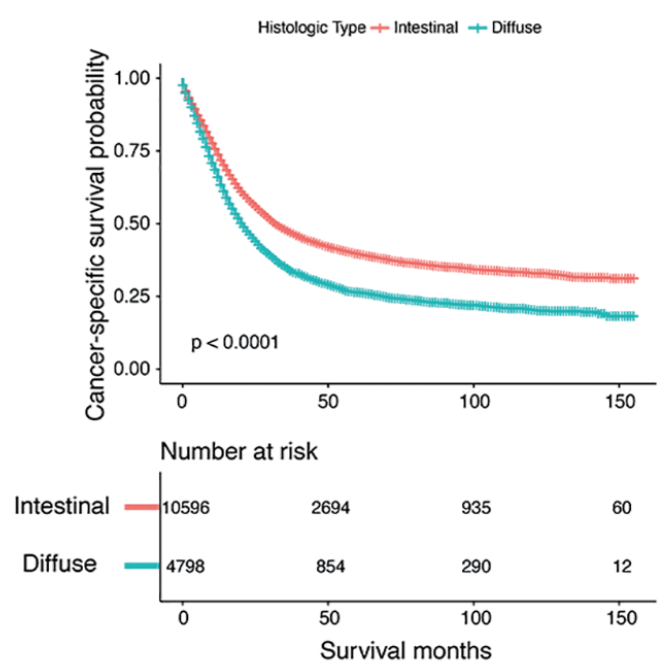

$\mathrm{F}$

M1-MX stage

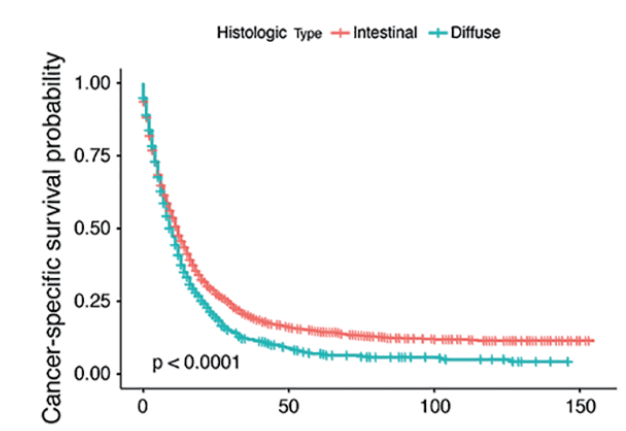

Intestinal $=$\begin{tabular}{cccc}
\multicolumn{4}{l}{ Number at risk } \\
1722 & 174 & 70 & 6 \\
1013 & 55 & 15 & 0 \\
\hline 0 & 50 & 100 & 150 \\
& & Survival months
\end{tabular} 
G
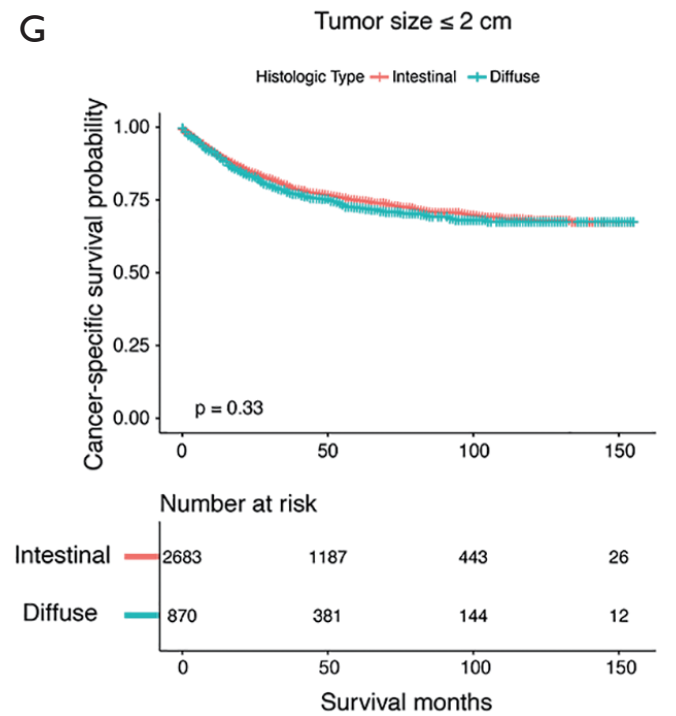

$\mathrm{H}$
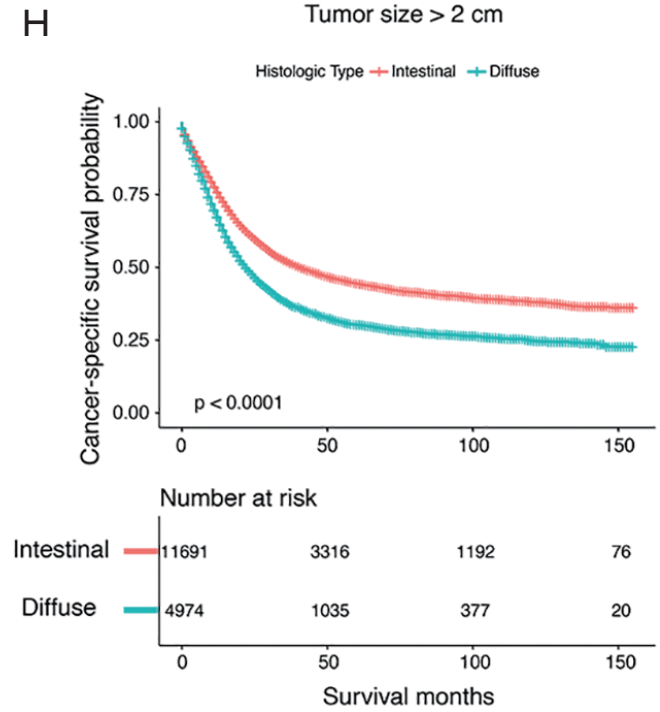

Figure 4 Kaplan-Meier analysis of cancer-specific survival based on Lauren's classification in subgroups. Kaplan-Meier analysis of cancer-specific survival based on Lauren's classification in the (A) moderately or well differentiated subgroup; (B) poorly differentiated or undifferentiated subgroup; (C) T1 stage subgroup; (D) T2-TX stage subgroup; (E) M0 stage subgroup; (F) M1-MX stage subgroup; (G) tumor size $\leq 2 \mathrm{~cm}$ subgroup; (H) tumor size $>2 \mathrm{~cm}$ subgroup.

( $N=20,218)$. Our results revealed that after adjusting potential confounders, diffuse-type gastric adenocarcinoma showed an overall poorer prognosis than the intestinal type, yet in patients with T1 stage and tumor size $<2 \mathrm{~cm}$, the prognosis of the diffuse type was similar to that of the intestinal type. This indicated that diffuse-type gastric adenocarcinoma was an independent risk factor associated with a poorer prognosis, except for patients with T1 stage and tumor size of less than $2 \mathrm{~cm}$.

According to previous reports, diffuse-type gastric adenocarcinoma is associated with younger female patients and exhibits a shorter survival and worse prognosis than the intestinal type (14-18). Our results showed that patients with diffuse-type were younger females with shorter CSS, which is consistent with previous studies. Our results also showed that the diffuse type of gastric adenocarcinoma was significantly associated with advanced stages compared with the intestinal type. This is also consistent with a previous report that revealed that diffuse type was an independent predictor of peritoneal metastases using staging laparoscopy (24).

Although Lauren's classification has been proposed for over 50 years, this classification's clinical value remains controversial. Various studies have investigated the association between Lauren's classification and prognosis of gastric adenocarcinoma with significantly varying results.
A recent meta-analysis showed that diffuse-type gastric adenocarcinoma had a poorer prognosis than patients with the intestinal type (14). However, the sample sizes of the included studies were relatively small, and the adjusted confounders in each study were quite different from the others, which may reduce the reliability and confidence of the pooled results. Furthermore, among all 73 included studies, only six included a sample size of more than 2,000 cases. Notably, our findings were consistent with the six studies with large sample sizes, which showed that patients with the diffuse type had a worse prognosis than patients with the intestinal type (HR: 1.085-1.498). The crude HR we calculated in the present study was $1.44(95 \%$ CI, 1.38-1.50), and the adjusted HR was 1.19 (95\% CI, $1.14-1.25)$ and 1.20 (95\% CI, 1.15-1.26) in model I and model II, respectively. These crude and adjusted HRs were in the range of HRs reported in the six studies above. The variance of the adjusted confounders may have caused the minor difference in the HRs. One of the six studies (sample size: 9,325 cases) also used the SEER database to analyze the association between Lauren's classification and prognosis of gastric adenocarcinoma and found that the diffuse type had a worse prognosis, with an HR of 1.347 (95\% CI, 1.264-1.434) (25). The confounders they adjusted for included age, sex, race, socioeconomic status, site, summary stage, differentiation, surgery, chemotherapy, 
radiation therapy, hospital size, academic institution, and year of diagnosis. However, tumor size, race, and marital status, which were documented to influence gastric adenocarcinoma prognosis (26-28), were not included in their study. In the present study, we used strict statistical adjustment to minimize residual confounders, and thus our results might be more reliable. To further validate our findings, we performed sensitivity analyses, including conducting PSM and establishing a competing risk model. Our sensitivity analyses showed that the diffuse type had a worse prognosis [HR (PSM), 1.23; 95\% CI, 1.10-1.36; SHR, 1.32; 95\% CI, 1.23-1.41], which bolstered the strength of our results. Our previous reports have suggested that different stomach parts express different glands and exhibit various clinicopathological features (29). However, few studies reported the impact of the mucosal origin on Lauren's classification in GCs. Here, the results based on the mucosal origins showed that the diffuse-type group showed a significantly higher risk of cancer-specific death than the intestinal-type group in different mucosa origins.

Interestingly, we also noticed that several studies suggested that patients with diffuse-type gastric adenocarcinoma had a similar or even a better prognosis than those with the intestinal type (30-37). However, these studies' sample sizes were relatively small, and only KaplanMeier analyses with log-rank tests were performed, which could not rule out the influence of potential confounders. Recently, two studies based on the SEER database suggested that the diffuse type showed a comparable or better prognosis than the intestinal type. The first study by Tang et al. revealed that diffuse-type early gastric cancer (EGC) had a better prognosis than intestinal-type EGC by using PSM for adjusting confounders. However, after matching, only 2,672 cases were included in their study, which might weaken the whole sample's representativeness (23). Herein, we performed multivariate regression first and then conducted PSM, and established a competing risk model to perform sensitivity analysis. The comprehensive statistical analyses fully adjusted for residual confounders, thus making the results more reliable. Another study by Li et al. only included EGC and performed the comprehensive statistical analysis, including multivariate regression and PSM, to adjust for confounders (38). They found that diffuse-type EGC may have a comparable prognosis to intestinal-type EGC. Notably, this is consistent with our findings. Our subgroup analysis showed that in patients with T1 stage and tumor size $<2 \mathrm{~cm}$, the diffuse type had a comparable survival rate with the intestinal type. The British Society of Gastroenterology's latest guidelines recommended that complete (R0) endoscopic resection is only suitable for patients with the intestinal type and is not suitable for those with the diffuse type (13). However, our results may provide evidence that endoscopic submucosal dissection is suitable for intestinal-type patients and diffuse-type patients when the tumor is at the T1 stage and the tumor size is smaller than $2 \mathrm{~cm}$.

However, this study has several limitations that should be noted. Firstly, we did not rule out all the cases containing missing data, which might have influenced the results' strength. To minimize selection bias, we included as many cases as possible. The missing data in each item were listed and calculated in the regression formula as a separate group. Based on the univariable Cox regression results, we combined the missing data groups to groups with similar effect coefficients when performing survival and subgroup analyses. Secondly, lymphatic vessel involvement and mixed type information was not available in the SEER database. As noted previously, lymphatic vessel involvement is considered a significant prognostic factor for EGC instead of $\mathrm{N}$ stage, and thus may have potential influence when performing subgroup analysis. Further studies should include lymphatic vessel involvement as a potential confounder to evaluate the association between Lauren's classification and prognosis of EGC. The association between the mixed type and prognosis of gastric adenocarcinoma is still controversial; however, we cannot investigate this important topic due to limited information. In the future, the characteristics and clinical value of the mixed type should be fully investigated.

\section{Conclusions}

In this study, we found that diffuse-type gastric adenocarcinoma had an overall poorer prognosis than the intestinal type. However, in patients with T1 stage and tumor size of less than $2 \mathrm{~cm}$, the diffuse type had a comparable survival rate with the intestinal type. This study may deepen our understanding of Lauren's classification and provide evidence that endoscopic submucosal dissection is suitable for intestinal-type patients and diffuse-type patients when the tumor is at T1 stage, the tumor size is smaller than $2 \mathrm{~cm}$.

\section{Acknowledgments}

Funding: This study was funded by the National Natural Science Foundation of China (grants no. 81672935 and 
81871947), the Natural Science Foundation of Jiangsu (grant no. SBK2019022491).

\section{Footnote}

Reporting Checklist: The authors have completed the STROBE reporting checklist. Available at http://dx.doi. org/10.21037/atm-20-7953

Data Sharing Statement: Available at http://dx.doi. org/10.21037/atm-20-7953

Peer Review File: Available at http://dx.doi.org/10.21037/ atm-20-7953

Conflicts of Interest: All authors have completed the ICMJE uniform disclosure form (available at http://dx.doi. org/10.21037/atm-20-7953). The authors have no conflicts of interest to declare.

Ethical Statement: The authors are accountable for all aspects of the work in ensuring that questions related to the accuracy or integrity of any part of the work are appropriately investigated and resolved. The study was conducted in accordance with the Declaration of Helsinki (as revised in 2013). Informed consent or ethical approval was not required since SEER database only contain deidentified data and is available to the public.

Open Access Statement: This is an Open Access article distributed in accordance with the Creative Commons Attribution-NonCommercial-NoDerivs 4.0 International License (CC BY-NC-ND 4.0), which permits the noncommercial replication and distribution of the article with the strict proviso that no changes or edits are made and the original work is properly cited (including links to both the formal publication through the relevant DOI and the license). See: https://creativecommons.org/licenses/by-nc-nd/4.0/.

\section{References}

1. Nakamura K, Sugano H, Takagi K. Carcinoma of the stomach in incipient phase: its histogenesis and histological appearances. Gan 1968;59:251-8.

2. Ajani JA, Lee J, Sano T, et al. Gastric adenocarcinoma. Nat Rev Dis Primers 2017;3:17036.

3. Van Cutsem E, Sagaert X, Topal B, et al. Gastric cancer. Lancet 2016;388:2654-64.
4. Vauhkonen M, Vauhkonen H, Sipponen P. Pathology and molecular biology of gastric cancer. Best Pract Res Clin Gastroenterol 2006;20:651-74.

5. Oue N, Oshimo Y, Nakayama H, et al. DNA methylation of multiple genes in gastric carcinoma: association with histological type and CpG island methylator phenotype. Cancer Sci 2003;94:901-5.

6. Yasui W, Oue N, Ito R, et al. Search for new biomarkers of gastric cancer through serial analysis of gene expression and its clinical implications. Cancer Sci 2004;95:385-92.

7. Oue N, Sentani K, Sakamoto N, et al. Clinicopathologic and molecular characteristics of gastric cancer showing gastric and intestinal mucin phenotype. Cancer Sci 2015;106:951-8.

8. Lauren P. The Two Histological Main Types of Gastric Carcinoma: Diffuse and So-Called Intestinal-Type Carcinoma. An Attempt at a Histo-Clinical Classification. Acta Pathol Microbiol Scand 1965;64:31-49.

9. Huang JQ, Sridhar S, Chen Y, et al. Meta-analysis of the relationship between Helicobacter pylori seropositivity and gastric cancer. Gastroenterology 1998;114:1169-79.

10. Correa P. Human gastric carcinogenesis: a multistep and multifactorial process--First American Cancer Society Award Lecture on Cancer Epidemiology and Prevention. Cancer Res 1992;52:6735-40.

11. Watanabe M, Kato J, Inoue I, et al. Development of gastric cancer in nonatrophic stomach with highly active inflammation identified by serum levels of pepsinogen and Helicobacter pylori antibody together with endoscopic rugal hyperplastic gastritis. Int J Cancer 2012;131:2632-42.

12. Nardone G, Rocco A, Malfertheiner P. Review article: helicobacter pylori and molecular events in precancerous gastric lesions. Aliment Pharmacol Ther 2004;20:261-70.

13. Banks M, Graham D, Jansen M, et al. British Society of Gastroenterology guidelines on the diagnosis and management of patients at risk of gastric adenocarcinoma. Gut 2019;68:1545-75.

14. Petrelli F, Berenato R, Turati L, et al. Prognostic value of diffuse versus intestinal histotype in patients with gastric cancer: a systematic review and meta-analysis. J Gastrointest Oncol 2017;8:148-63.

15. Adachi $Y$, Yasuda K, Inomata M, et al. Pathology and prognosis of gastric carcinoma: well versus poorly differentiated type. Cancer 2000;89:1418-24.

16. Ribeiro MM, Sarmento JA, Sobrinho Simoes MA, et al. Prognostic significance of Lauren and Ming classifications and other pathologic parameters in gastric carcinoma. Cancer 1981;47:780-4. 
17. Lee T, Tanaka H, Ohira M, et al. Clinical impact of the extent of lymph node micrometastasis in undifferentiatedtype early gastric cancer. Oncology 2014;86:244-52.

18. Chen YC, Fang WL, Wang RF, et al. Clinicopathological Variation of Lauren Classification in Gastric Cancer. Pathol Oncol Res 2016;22:197-202.

19. Pyo JH, Ahn S, Lee H, et al. Clinicopathological Features and Prognosis of Mixed-Type T1a Gastric Cancer Based on Lauren's Classification. Ann Surg Oncol 2016;23:784-91.

20. Pyo JH, Lee H, Min BH, et al. Early gastric cancer with a mixed-type Lauren classification is more aggressive and exhibits greater lymph node metastasis. J Gastroenterol 2017;52:594-601.

21. Chiu CT, Kuo CJ, Yeh TS, et al. Early signet ring cell gastric cancer. Dig Dis Sci 2011;56:1749-56.

22. Kwon KJ, Shim KN, Song EM, et al. Clinicopathological characteristics and prognosis of signet ring cell carcinoma of the stomach. Gastric Cancer 2014;17:43-53.

23. Tang CT, Zeng L, Yang J, et al. Analysis of the Incidence and Survival of Gastric Cancer Based on the Lauren Classification: A Large Population-Based Study Using SEER. Front Oncol 2020;10:1212.

24. Rawicz-Pruszynski K, Mielko J, Pudlo K, et al. Yield of staging laparoscopy in gastric cancer is influenced by Lauren histologic subtype. J Surg Oncol 2019;120:1148-53.

25. Kunz PL, Gubens M, Fisher GA, et al. Long-term survivors of gastric cancer: a California population-based study. J Clin Oncol 2012;30:3507-15.

26. Hirabayashi S, Kosugi S, Isobe Y, et al. Development and external validation of a nomogram for overall survival after curative resection in serosa-negative, locally advanced gastric cancer. Ann Oncol 2014;25:1179-84.

27. Li H, Wang C, Wei Z, et al. Differences in the prognosis of gastric cancer patients of different sexes and races and the molecular mechanisms involved. Int J Oncol 2019;55:1049-68.

28. Jin JJ, Wang W, Dai FX, et al. Marital status and survival in patients with gastric cancer. Cancer Med 2016;5:1821-9.

Cite this article as: Tang D, Ni M, Zhu H, Cao J, Zhou L, Shen S, Peng C, Lv Y, Xu G, Wang L, Zou X. Differential prognostic implications of gastric adenocarcinoma based on Lauren's classification: a Surveillance, Epidemiology, and End Results (SEER)-based cohort study. Ann Transl Med 2021;9(8):646. doi: 10.21037/atm-20-7953
29. Huang Q, Li R, Xu GF, et al. Emerging evidence supports grouping by location of early gastric carcinoma for appropriate clinical management in Chinese patients. J Dig Dis 2018;19:730-6.

30. An JY, Baik YH, Choi MG, et al. The prognosis of gastric cardia cancer after R0 resection. Am J Surg 2010;199:725-9.

31. Atmaca A, Werner D, Pauligk C, et al. The prognostic impact of epidermal growth factor receptor in patients with metastatic gastric cancer. BMC Cancer 2012;12:524.

32. Bilici A, Seker M, Ustaalioglu BB, et al. Prognostic significance of perineural invasion in patients with gastric cancer who underwent curative resection. Ann Surg Oncol 2010;17:2037-44.

33. Eom BW, Kim YW, Lee SE, et al. Survival and surgical outcomes after laparoscopy-assisted total gastrectomy for gastric cancer: case-control study. Surg Endosc 2012;26:3273-81.

34. Marano L, Boccardi V, Braccio B, et al. Comparison of the 6th and 7th editions of the AJCC/UICC TNM staging system for gastric cancer focusing on the "N" parameterrelated survival: the monoinstitutional NodUs Italian study. World J Surg Oncol 2015;13:215.

35. Shim HJ, Yun JY, Hwang JE, et al. Prognostic factor analysis of third-line chemotherapy in patients with advanced gastric cancer. Gastric Cancer 2011;14:249-56.

36. Otsuki S, Inokuchi M, Enjoji M, et al. Vimentin expression is associated with decreased survival in gastric cancer. Oncol Rep 2011;25:1235-42.

37. Tan IB, Ivanova T, Lim KH, et al. Intrinsic subtypes of gastric cancer, based on gene expression pattern, predict survival and respond differently to chemotherapy. Gastroenterology 2011;141: 476-85, 485.e1-11.

38. Li ZY, Zhang QW, Teng LM, et al. Comparable rates of lymph node metastasis and survival between diffuse type and intestinal type early gastric cancer patients: a large population-based study. Gastrointest Endosc 2019;90:84-95.e10. 
A
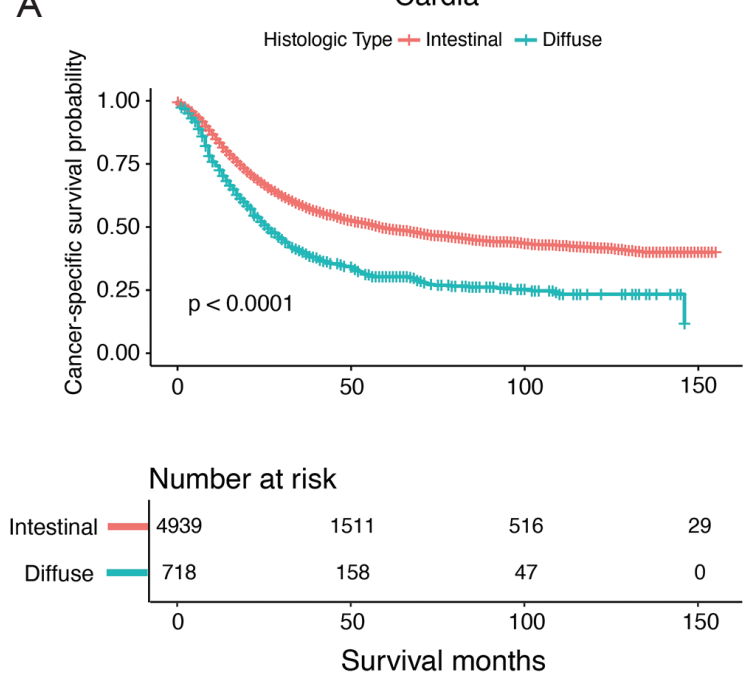

$\mathrm{C}$

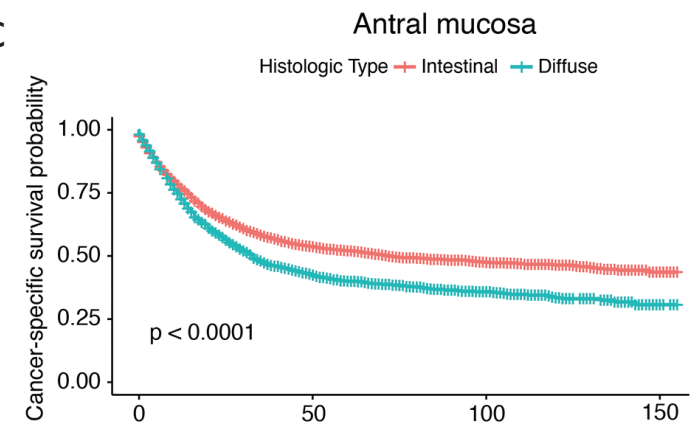

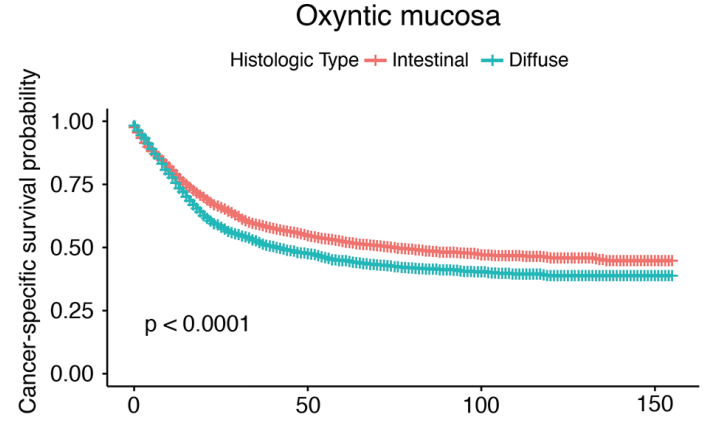

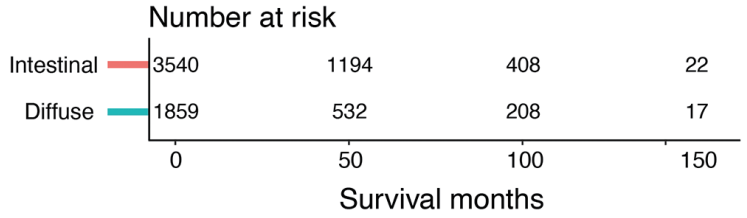

Stomach, NOS

D

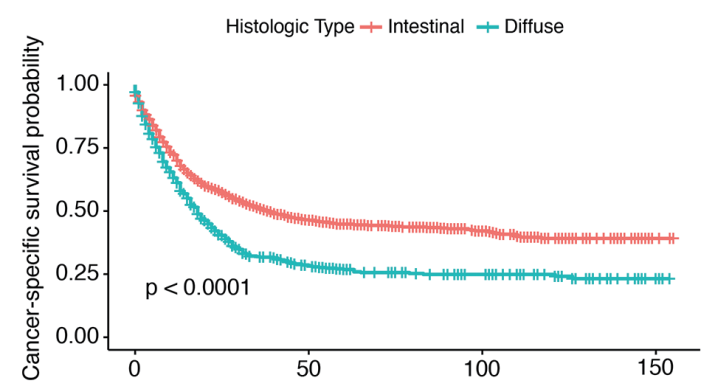

$E$

Overlapping lesions

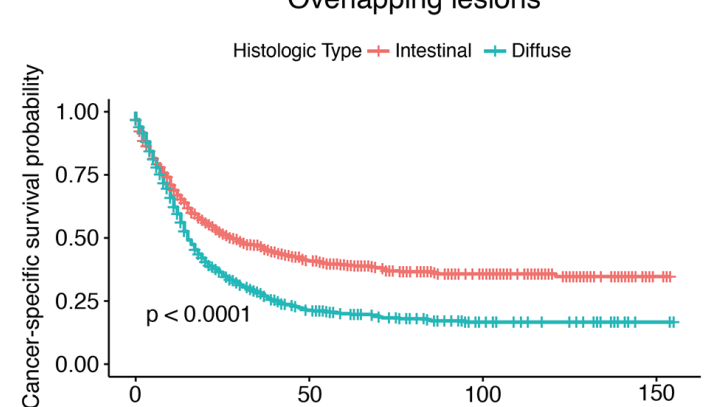

Intestinal $=$\begin{tabular}{cccc} 
Number at risk \\
1134 & 325 & 139 & 7 \\
689 & 120 & 54 & 4 \\
\hline 0 & 50 & 100 & 150
\end{tabular}

Survival months

$50 \quad 100 \quad 150$

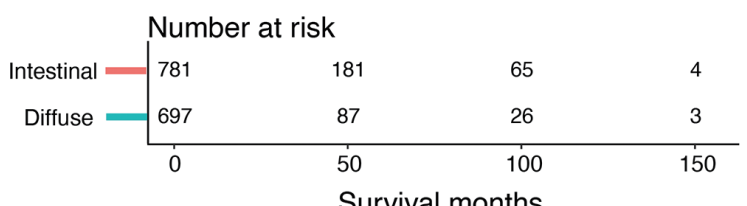

Figure S1 Kaplan-Meier analysis of cancer-specific survival based on Lauren's classification in subgroups of primate sites. (A) KaplanMeier analysis of cancer-specific survival based on Lauren's classification in cardia subgroup; (B) Kaplan-Meier analysis of cancer-specific survival based on Lauren's classification in oxyntic mucosa subgroup; (C) Kaplan-Meier analysis of cancer-specific survival based on Lauren's classification in antral mucosa subgroup; (D) Kaplan-Meier analysis of cancer-specific survival based on Lauren's classification in stomach, NOS subgroup; (E) Kaplan-Meier analysis of cancer-specific survival based on Lauren's classification in overlapping lesions subgroup. NOS, not otherwise specified.

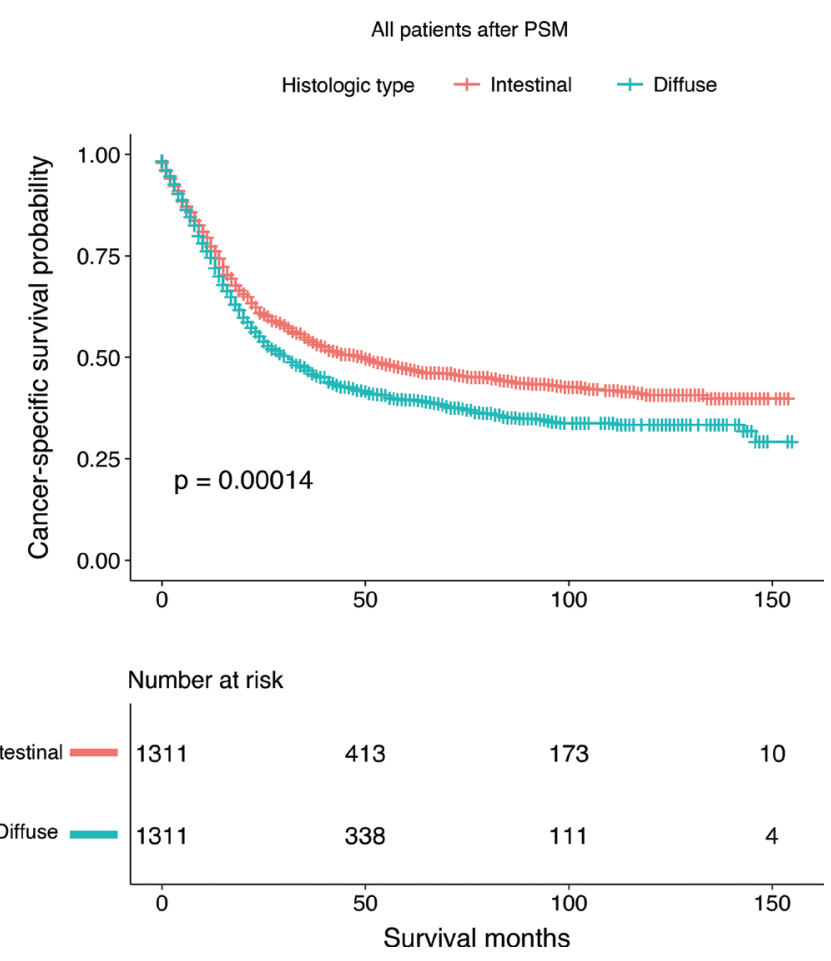

Figure S2 Kaplan-Meier analysis of cancer-specific survival based on Lauren's classification after propensity score matching. 
Table S1 Baseline characteristics of the participants before and after propensity score matching

\begin{tabular}{|c|c|c|c|c|c|c|c|c|}
\hline \multirow{2}{*}{ Variables } & \multicolumn{4}{|c|}{ Before PSM } & \multicolumn{4}{|c|}{ After PSM } \\
\hline & All patients $(\mathrm{N}=20,218)$ & Intestinal $(N=14,374)$ & Diffuse $(N=5,844)$ & $P$ value & All patients ( $\mathrm{N}=2,622)$ & Intestinal $(\mathrm{N}=1,311)$ & Diffuse $(\mathrm{N}=1,311)$ & $P$ value \\
\hline Age (years) & $65.6 \pm 13.4$ & $67.5 \pm 12.6$ & $60.9 \pm 14.0$ & $<0.001$ & $66.2 \pm 11.0$ & $66.15 \pm 11.01$ & $66.15 \pm 11.01$ & 1.0000 \\
\hline Sex & & & & $<0.001$ & & & & $<0.0001$ \\
\hline Male & $12,746(63.0 \%)$ & $9,739(67.8 \%)$ & 3,007 (51.5\%) & & $1,599(61.0 \%)$ & $861(65.7 \%)$ & 738 (56.3\%) & \\
\hline Female & 7,472 (37.0\%) & 4,635 (32.2\%) & $2,837(48.5 \%)$ & & $1,023(39.0 \%)$ & $450(34.3 \%)$ & $573(43.7 \%)$ & \\
\hline Year & & & & 0.606 & & & & 0.0686 \\
\hline 2004-2007 & 7,174 (35.5\%) & $5,073(35.3 \%)$ & 2,101 (36.0\%) & & $945(36.0 \%)$ & $500(38.1 \%)$ & $445(33.9 \%)$ & \\
\hline 2008-2011 & 6,635 (32.8\%) & $4,720(32.8 \%)$ & $1,915(32.8 \%)$ & & 879 (33.5\%) & $419(32 \%)$ & 460 (35.1\%) & \\
\hline 2011-2015 & $6,409(31.7 \%)$ & $4,581(31.9 \%)$ & $1,828(31.3 \%)$ & & 798 (30.4\%) & 392 (29.9\%) & $406(31 \%)$ & \\
\hline Primary site & & & & $<0.001$ & & & & 1.0000 \\
\hline Cardia & $5,657(28.0 \%)$ & 4,939 (34.4\%) & $718(12.3 \%)$ & & $684(26.1 \%)$ & $342(26.1 \%)$ & $342(26.1 \%)$ & \\
\hline Fundus of stomach & $576(2.8 \%)$ & $412(2.9 \%)$ & $164(2.8 \%)$ & & $18(0.7 \%)$ & $9(0.7 \%)$ & $9(0.7 \%)$ & \\
\hline Lesser curvature of stomach & $2,140(10.6 \%)$ & $1,404(9.8 \%)$ & $736(12.6 \%)$ & & $300(11.4 \%)$ & $150(11.4 \%)$ & $150(11.4 \%)$ & \\
\hline Greater curvature of stomach & $883(4.4 \%)$ & $589(4.1 \%)$ & $294(5.0 \%)$ & & $54(2.1 \%)$ & $27(2.1 \%)$ & $27(2.1 \%)$ & \\
\hline Body of stomach & $1,800(8.9 \%)$ & $1,135(7.9 \%)$ & $665(11.4 \%)$ & & $198(7.6 \%)$ & $99(7.6 \%)$ & $99(7.6 \%)$ & \\
\hline Gastric antrum & $5,075(25.1 \%)$ & 3,429 (23.9\%) & $1,646(28.2 \%)$ & & $950(36.2 \%)$ & 475 (36.2\%) & 475 (36.2\%) & \\
\hline Pylorus & $786(3.9 \%)$ & $551(3.8 \%)$ & $235(4.0 \%)$ & & $46(1.8 \%)$ & $23(1.8 \%)$ & $23(1.8 \%)$ & \\
\hline Stomach, NOS & $1,823(9.0 \%)$ & $1,134(7.9 \%)$ & $689(11.8 \%)$ & & $174(6.6 \%)$ & $87(6.6 \%)$ & $87(6.6 \%)$ & \\
\hline Overlapping lesion of stomach & $1,478(7.3 \%)$ & $781(5.4 \%)$ & $697(11.9 \%)$ & & $198(7.6 \%)$ & $99(7.6 \%)$ & $99(7.6 \%)$ & \\
\hline Grade & & & & $<0.001$ & & & & 1.0000 \\
\hline Moderately differentiated or well differentiated & 6,142 (30.4\%) & $5,989(41.7 \%)$ & $153(2.6 \%)$ & & $76(2.9 \%)$ & $38(2.9 \%)$ & $38(2.9 \%)$ & \\
\hline Poorly differentiated or undifferentiated & $12,711(62.9 \%)$ & 7,455 (51.9\%) & $5,256(89.9 \%)$ & & $2,478(94.5 \%)$ & $1,239(94.5 \%)$ & $1,239(94.5 \%)$ & \\
\hline Unknown & $1,365(6.8 \%)$ & $930(6.5 \%)$ & $435(7.4 \%)$ & & $68(2.6 \%)$ & $34(2.6 \%)$ & $34(2.6 \%)$ & \\
\hline T stage & & & & $<0.001$ & & & & 1.0000 \\
\hline $\mathrm{T} 1$ & 4,824 (23.9\%) & $3,778(26.3 \%)$ & 1,046 (17.9\%) & & $590(22.5 \%)$ & $295(22.5 \%)$ & 295 (22.5\%) & \\
\hline T2a & 2,183 (10.8\%) & $1,687(11.7 \%)$ & 496 (8.5\%) & & $140(5.3 \%)$ & $70(5.3 \%)$ & $70(5.3 \%)$ & \\
\hline T2b & $6,417(31.7 \%)$ & 4,673 (32.5\%) & $1,744(29.8 \%)$ & & $1,042(39.7 \%)$ & $521(39.7 \%)$ & $521(39.7 \%)$ & \\
\hline T2, NOS & $134(0.7 \%)$ & $105(0.7 \%)$ & $29(0.5 \%)$ & & $0(0)$ & $0(0 \%)$ & $0(0 \%)$ & \\
\hline T3 & 4,507 (22.3\%) & 2,764 (19.2\%) & $1,743(29.8 \%)$ & & $700(26.7 \%)$ & $350(26.7 \%)$ & $350(26.7 \%)$ & \\
\hline T4 & $1,750(8.7 \%)$ & $1,059(7.4 \%)$ & $691(11.8 \%)$ & & $140(5.3 \%)$ & $70(5.3 \%)$ & $70(5.3 \%)$ & \\
\hline$T X$ & $403(2.0 \%)$ & $308(2.1 \%)$ & $95(1.6 \%)$ & & $10(0.4 \%)$ & $5(0.4 \%)$ & $5(0.4 \%)$ & \\
\hline $\mathrm{N}$ stage & & & & $<0.001$ & & & & 1.0000 \\
\hline No & $8,155(40.3 \%)$ & 6,274 (43.6\%) & 1,881 (32.2\%) & & 872 (33.3\%) & 436 (33.3\%) & 436 (33.3\%) & \\
\hline $\mathrm{N} 1$ & 7,332 (36.3\%) & 5,401 (37.6\%) & 1,931 (33.0\%) & & $1,096(41.8 \%)$ & 548 (41.8\%) & 548 (41.8\%) & \\
\hline N2 & 3,124 (15.5\%) & $1,853(12.9 \%)$ & $1,271(21.7 \%)$ & & 516 (19.7\%) & 258 (19.7\%) & 258 (19.7\%) & \\
\hline N3 & $1,253(6.2 \%)$ & 594 (4.1\%) & 659 (11.3\%) & & $130(5.0 \%)$ & $65(5 \%)$ & $65(5 \%)$ & \\
\hline $\mathrm{NX}$ & 354 (1.8\%) & $252(1.8 \%)$ & $102(1.7 \%)$ & & $8(0.3 \%)$ & $4(0.3 \%)$ & $4(0.3 \%)$ & \\
\hline M stage & & & & $<0.001$ & & & & 1.0000 \\
\hline Mo & $17,483(86.5 \%)$ & 12,652 (88.0\%) & $4,831(82.7 \%)$ & & 2,490 (95.0\%) & 1,245 (95\%) & 1,245 (95\%) & \\
\hline M1 & 2,378 (11.8\%) & $1,457(10.1 \%)$ & 921 (15.8\%) & & $126(4.8 \%)$ & $63(4.8 \%)$ & $63(4.8 \%)$ & \\
\hline MX & $357(1.8 \%)$ & 265 (1.8\%) & $92(1.6 \%)$ & & $6(0.2 \%)$ & $3(0.2 \%)$ & $3(0.2 \%)$ & \\
\hline Operation & & & & $<0.001$ & & & & 0.0723 \\
\hline Surgery & 19,272 (95.3\%) & 13,534 (94.2\%) & $5,738(98.2 \%)$ & & 2,584 (98.6\%) & $1,286(98.1 \%)$ & 1,298 (99\%) & \\
\hline Endoscopy & 946 (4.7\%) & $840(5.8 \%)$ & $106(1.8 \%)$ & & $38(1.4 \%)$ & $25(1.9 \%)$ & $13(1 \%)$ & \\
\hline Radiation & & & & $<0.001$ & & & & 0.0347 \\
\hline None/unknown & 13,531 (66.9\%) & 9,728 (67.7\%) & 3,803 (65.1\%) & & $1,638(62.5 \%)$ & $830(63.3 \%)$ & 808 (61.6\%) & \\
\hline Yes & 6,687 (33.1\%) & $4,646(32.3 \%)$ & 2,041 (34.9\%) & & 984 (37.5\%) & 481 (36.7\%) & 503 (38.4\%) & \\
\hline Chemotherapy & & & & $<0.001$ & & & & 0.3678 \\
\hline No/unknown & 9,931 (49.1\%) & 7,508 (52.2\%) & 2,423 (41.5\%) & & $1,220(46.5 \%)$ & 622 (47.4\%) & 598 (45.6\%) & \\
\hline Yes & $10,287(50.9 \%)$ & 6,866 (47.8\%) & $3,421(58.5 \%)$ & & $1,402(53.5 \%)$ & 689 (52.6\%) & 713 (54.4\%) & \\
\hline Tumor size (cm) & & & & $<0.001$ & & & & 1.0000 \\
\hline $\mathrm{T} \leq 2$ & $3,553(17.6 \%)$ & 2,683 (18.7\%) & 870 (14.9\%) & & 434 (16.6\%) & 217 (16.6\%) & 217 (16.6\%) & \\
\hline $2<T \leq 3$ & 2,551 (12.6\%) & $1,860(12.9 \%)$ & 691 (11.8\%) & & $256(9.8 \%)$ & $128(9.8 \%)$ & $128(9.8 \%)$ & \\
\hline $3<\mathrm{T} \leq 5$ & 4,724 (23.4\%) & 3,584 (24.9\%) & $1,140(19.5 \%)$ & & 594 (22.7\%) & 297 (22.7\%) & 297 (22.7\%) & \\
\hline $\mathrm{T}>5$ & 6,512 (32.2\%) & 4,229 (29.4\%) & 2,283 (39.1\%) & & $1,118(42.6 \%)$ & 559 (42.6\%) & 559 (42.6\%) & \\
\hline Unknown & 2,878 (14.2\%) & 2,018 (14.0\%) & 860 (14.7\%) & & $220(8.4 \%)$ & $110(8.4 \%)$ & $110(8.4 \%)$ & \\
\hline Race & & & & $<0.001$ & & & & 0.1424 \\
\hline White & 13,649 (67.5\%) & $9,790(68.1 \%)$ & 3,859 (66.0\%) & & $1,723(65.7 \%)$ & 843 (64.3\%) & 880 (67.1\%) & \\
\hline Asian or Pacific Islander & $3,714(18.4 \%)$ & 2,538 (17.7\%) & $1,176(20.1 \%)$ & & $565(21.5 \%)$ & $279(21.3 \%)$ & $286(21.8 \%)$ & \\
\hline Black & $2,615(12.9 \%)$ & $1,894(13.2 \%)$ & $721(12.3 \%)$ & & $309(11.8 \%)$ & $175(13.3 \%)$ & 134 (10.2\%) & \\
\hline American Indian/Alaska Native & $177(0.9 \%)$ & $114(0.8 \%)$ & $63(1.1 \%)$ & & $17(0.6 \%)$ & $9(0.7 \%)$ & $8(0.6 \%)$ & \\
\hline Unknown & $63(0.3 \%)$ & $38(0.3 \%)$ & $25(0.4 \%)$ & & $8(0.3 \%)$ & $5(0.4 \%)$ & $3(0.2 \%)$ & \\
\hline Insurance & & & & $<0.001$ & & & & 0.0531 \\
\hline Insured & 11,626 (57.5\%) & $8,378(58.3 \%)$ & $3,248(55.6 \%)$ & & $1,512(57.7 \%)$ & $730(55.7 \%)$ & $782(59.6 \%)$ & \\
\hline Medicaid & 2,425 (12.0\%) & $1,697(11.8 \%)$ & 728 (12.5\%) & & $308(11.7 \%)$ & $155(11.8 \%)$ & $153(11.7 \%)$ & \\
\hline Uninsured & $459(2.3 \%)$ & $295(2.1 \%)$ & $164(2.8 \%)$ & & $53(2.0 \%)$ & $34(2.6 \%)$ & $19(1.4 \%)$ & \\
\hline Unknown & $5,708(28.2 \%)$ & 4,004 (27.9\%) & $1,704(29.2 \%)$ & & 749 (28.6\%) & $392(29.9 \%)$ & $357(27.2 \%)$ & \\
\hline Marital status & & & & $<0.001$ & & & & 0.9833 \\
\hline Married & $12,309(60.9 \%)$ & $8,736(60.8 \%)$ & $3,573(61.1 \%)$ & & $1,654(63.1 \%)$ & 829 (63.2\%) & 825 (62.9\%) & \\
\hline Divorced or separated & $1,826(9.0 \%)$ & $1,275(8.9 \%)$ & $551(9.4 \%)$ & & $229(8.7 \%)$ & $110(8.4 \%)$ & $119(9.1 \%)$ & \\
\hline Widowed & 2,659 (13.2\%) & 2,036 (14.2\%) & $623(10.7 \%)$ & & $343(13.1 \%)$ & $170(13 \%)$ & $173(13.2 \%)$ & \\
\hline Single (never married) & 2,619 (13.0\%) & $1,752(12.2 \%)$ & $867(14.8 \%)$ & & $303(11.6 \%)$ & $153(11.7 \%)$ & $150(11.4 \%)$ & \\
\hline Unmarried or domestic partner & $18(0.1 \%)$ & $14(0.1 \%)$ & $4(0.1 \%)$ & & $2(0.1 \%)$ & $1(0.1 \%)$ & $1(0.1 \%)$ & \\
\hline Unknown & 787 (3.9\%) & $561(3.9 \%)$ & $226(3.9 \%)$ & & $91(3.5 \%)$ & $48(3.7 \%)$ & $43(3.3 \%)$ & \\
\hline Survival months, median (interquartile range) & $25.0(11.0-58.0)$ & $27.0(12.0-62.0)$ & $20.0(9.0-48.0)$ & $<0.001$ & $24.0(11.0-57.0)$ & $26.0(11.0-65.0)$ & $22.0(10.0-51.0)$ & 0.002 \\
\hline
\end{tabular}


Table S2 Univariable Cox regression analysis for cancer-specific survival in patients with gastric adenocarcinom

\begin{tabular}{|c|c|c|}
\hline Variable & $\beta / \mathrm{HR}(95 \% \mathrm{Cl})$ & $P$ value \\
\hline Age & $1.01(1.01,1.02)$ & $<0.0001$ \\
\hline \multicolumn{3}{|l|}{ Sex } \\
\hline Male & Reference & \\
\hline Female & $1.05(0.94,1.17)$ & 0.3632 \\
\hline \multicolumn{3}{|l|}{ Year } \\
\hline 2004-2007 & Reference & \\
\hline 2008-2011 & $0.91(0.81,1.03)$ & 0.1258 \\
\hline 2011-2015 & $0.76(0.66,0.88)$ & 0.0002 \\
\hline \multicolumn{3}{|l|}{ Primary site } \\
\hline Cardia & Reference & \\
\hline Fundus of stomach & $0.84(0.45,1.56)$ & 0.5742 \\
\hline Lesser curvature of stomach & $0.74(0.61,0.89)$ & 0.0020 \\
\hline Greater curvature of stomach & $0.54(0.35,0.84)$ & 0.0058 \\
\hline Body of stomach & $0.85(0.68,1.06)$ & 0.1506 \\
\hline Gastric antrum & $0.80(0.70,0.92)$ & 0.0015 \\
\hline Pylorus & $1.20(0.83,1.73)$ & 0.3284 \\
\hline Stomach, NOS & $1.13(0.91,1.41)$ & 0.2618 \\
\hline Overlapping lesion of stomach & $1.42(1.16,1.73)$ & 0.0005 \\
\hline \multicolumn{3}{|l|}{ Grade } \\
\hline Moderately differentiated or well differentiated & Reference & \\
\hline Poorly differentiated or undifferentiated & $2.23(1.48,3.37)$ & 0.0001 \\
\hline Unknown & $0.92(0.50,1.68)$ & 0.7780 \\
\hline \multicolumn{3}{|l|}{ Histologic type } \\
\hline Intestinal & Reference & \\
\hline Diffuse & $1.23(1.10,1.36)$ & 0.0002 \\
\hline \multicolumn{3}{|l|}{ T stage } \\
\hline T1 & Reference & \\
\hline T2a & $2.07(1.46,2.93)$ & $<0.0001$ \\
\hline $\mathrm{T} 2 \mathrm{~b}$ & $4.77(3.88,5.86)$ & $<0.0001$ \\
\hline T3 & $6.49(5.25,8.01)$ & $<0.0001$ \\
\hline T4 & $9.44(7.27,12.26)$ & $<0.0001$ \\
\hline TX & $2.98(1.10,8.09)$ & 0.0320 \\
\hline \multicolumn{3}{|l|}{ N stage } \\
\hline No & Reference & \\
\hline $\mathrm{N} 1$ & $3.37(2.89,3.93)$ & $<0.0001$ \\
\hline N2 & $5.32(4.49,6.30)$ & $<0.0001$ \\
\hline N3 & $7.89(6.25,9.95)$ & $<0.0001$ \\
\hline NX & $6.04(2.68,13.59)$ & $<0.0001$ \\
\hline \multicolumn{3}{|l|}{ M stage } \\
\hline Mo & Reference & \\
\hline M1 & $2.79(2.28,3.42)$ & $<0.0001$ \\
\hline MX & $1.60(0.60,4.28)$ & 0.3454 \\
\hline \multicolumn{3}{|l|}{ Operation } \\
\hline Surgery & Reference & \\
\hline Endoscopy & $0.47(0.25,0.88)$ & 0.0180 \\
\hline \multicolumn{3}{|l|}{ Radiation } \\
\hline None/unknown & Reference & \\
\hline Yes & $1.08(0.97,1.20)$ & 0.1755 \\
\hline Chemotherapy & & \\
\hline No/unknown & Reference & \\
\hline Yes & $1.25(1.13,1.40)$ & $<0.0001$ \\
\hline Tumor size (cm) & & \\
\hline $\mathrm{T} \leq 2$ & Reference & \\
\hline $2<T \leq 3$ & $2.37(1.78,3.17)$ & $<0.0001$ \\
\hline $3<\mathrm{T} \leq 5$ & $3.79(2.98,4.83)$ & $<0.0001$ \\
\hline $\mathrm{T}>5$ & $5.92(4.72,7.43)$ & $<0.0001$ \\
\hline Unknown & $2.79(2.08,3.75)$ & $<0.0001$ \\
\hline Race & & \\
\hline White & Reference & \\
\hline Asian or Pacific Islander & $0.73(0.63,0.84)$ & $<0.0001$ \\
\hline Black & $1.00(0.85,1.18)$ & 0.9817 \\
\hline American Indian/Alaska Native & $2.14(1.26,3.63)$ & 0.0047 \\
\hline Unknown & $0.19(0.03,1.34)$ & 0.0959 \\
\hline Insurance & & \\
\hline Insured & Reference & \\
\hline Medicaid & $1.25(1.05,1.48)$ & 0.0110 \\
\hline Uninsured & $1.05(0.70,1.58)$ & 0.7990 \\
\hline Unknown & $1.28(1.14,1.44)$ & $<0.0001$ \\
\hline Marital status & & \\
\hline Married & Reference & \\
\hline Divorced or separated & $1.33(1.11,1.60)$ & 0.0021 \\
\hline Widowed & $1.46(1.26,1.70)$ & $<0.0001$ \\
\hline Single (never married) & $1.04(0.87,1.23)$ & 0.6912 \\
\hline Unmarried or domestic partner & $6.71(1.67,26.93)$ & 0.0073 \\
\hline Unknown & $0.77(0.54,1.08)$ & 0.1274 \\
\hline
\end{tabular}

PSM, propensity score matching; NOS, not otherwise specified; $\mathrm{HR}$, hazard ratio; $\mathrm{Cl}$, confidence interval. 
Table S3 Multivariable Cox regression models evaluating the association between Lauren's classification and cancer-specific survival

\begin{tabular}{|c|c|c|c|c|c|c|}
\hline \multirow{2}{*}{$\begin{array}{l}\text { Lauren's } \\
\text { classification }\end{array}$} & \multicolumn{2}{|c|}{ Crude } & \multicolumn{2}{|c|}{ Model I } & \multicolumn{2}{|c|}{ Model II } \\
\hline & $\mathrm{HR}(95 \% \mathrm{Cl})$ & $P$ value & HR $(95 \% \mathrm{Cl})$ & $P$ value & $\mathrm{HR}(95 \% \mathrm{Cl})$ & $P$ value \\
\hline Intestinal & Reference & & Reference & & Reference & \\
\hline Diffuse & $1.23(1.10,1.36)$ & 0.0002 & $1.22(1.10,1.36)$ & 0.0002 & $1.22(1.10,1.36)$ & 0.0002 \\
\hline
\end{tabular}

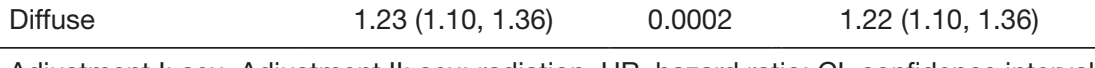

Table S4 Results of competing risks regression model with all the risk factors in patients with gastric adenocarcinoma

\begin{tabular}{|c|c|c|}
\hline Variables & HR $(95 \% \mathrm{Cl})$ & $P$ value \\
\hline Age & $1.01(1.01,1.01)$ & $<0.0001$ \\
\hline \multicolumn{3}{|l|}{ Sex } \\
\hline Male & Reference & \\
\hline Female & $0.97(0.91,1.03)$ & 0.3042 \\
\hline \multicolumn{3}{|l|}{ Year of diagnosis } \\
\hline 2004-2007 & Reference & \\
\hline 2008-2011 & $0.84(0.76,0.92)$ & 0.0003 \\
\hline 2011-2015 & $0.44(0.39,0.49)$ & $<0.0001$ \\
\hline \multicolumn{3}{|l|}{ Primary site } \\
\hline Cardia & Reference & \\
\hline Fundus of stomach & $0.77(0.65,0.91)$ & 0.0018 \\
\hline Lesser curvature of stomach & $0.64(0.58,0.70)$ & $<0.0001$ \\
\hline Greater curvature of stomach & $0.71(0.61,0.82)$ & $<0.0001$ \\
\hline Body of stomach & $0.72(0.65,0.80)$ & $<0.0001$ \\
\hline Gastric antrum & $0.71(0.66,0.77)$ & $<0.0001$ \\
\hline Pylorus & $0.82(0.71,0.95)$ & 0.0065 \\
\hline Stomach, NOS & $0.82(0.73,0.91)$ & 0.0003 \\
\hline Overlapping lesion of stomach & $0.79(0.70,0.89)$ & $<0.0001$ \\
\hline \multicolumn{3}{|l|}{ Grade } \\
\hline Moderately differentiated or well differentiated & Reference & \\
\hline Poorly differentiated or Undifferentiated & $1.23(1.15,1.31)$ & $<0.0001$ \\
\hline Unknown & $0.93(0.83,1.05)$ & 0.2568 \\
\hline \multicolumn{3}{|l|}{ Histologic type } \\
\hline Intestinal & Reference & \\
\hline Diffuse & $1.32(1.23,1.41)$ & $<0.0001$ \\
\hline
\end{tabular}

Tstage

$.32(1.23,1.41)$

$<0.0001$

T1

T2a

Reference

$1.60(1.42,1.80)<0.0001$

$2.47(2.23,2.74) \quad<0.0001$

$1.76(1.25,2.47) \quad 0.0011$

T2, NOS

T3

$3.21(2.89,3.58)<<0.0001$

$4.38(3.82,5.02) \quad<0.0001$

TX

$2.74(2.21,3.39)$

$<0.0001$

$\mathrm{N}$ stage

No

$\mathrm{N} 1$

Reference

$1.67(1.57,1.79)<0.0001$

$2.42(2.22,2.63) \quad<0.0001$

$3.34(2.91,3.83) \quad<0.0001$

$\begin{array}{ll}1.33(1.05,1.67) & 0.0161\end{array}$

NX

Mo

M1

Reference

$2.98(2.66,3.34) \quad<0.0001$

$1.31(1.04,1.64) \quad 0.0209$

Operation

Surgery

Endoscopy

Reference

$1.29(1.12,1.50)$

0.0005

None/unknown

Reference

$0.91(0.85,0.98)$

0.0146

Chemotherapy

No/unknown

Yes

Tumor size (cm)

$\mathrm{T} \leq 2$

$2<T \leq 3$

$3<\mathrm{T} \leq 5$

$T>5$

Unknown

Race

White

Asian or Pacific Islander

Black

American Indian/Alaska Native

Reference

$1.00(0.92,1.08)$

0.9243

Reference

$1.25(1.12,1.39)$

$1.25(1.13,1.38)$

$1.28(1.16,1.40)$

$1.41(1.27,1.57)$

$<0.0001$

Reference

$0.79(0.74,0.85)$

$1.00(0.91,1.08) \quad 0.9193$

$\begin{array}{ll}1.51(1.09,2.09) & 0.0122\end{array}$

$0.14(0.06,0.34) \quad<0.0001$

Insured

Medicaid

Uninsured

Unknown

Marital status

Married

Divorced or separated

Widowed

Single (never married)

Unmarried or domestic partner

\section{Reference}

$0.99(0.91,1.08) \quad 0.8124$

$0.93(0.78,1.11) \quad 0.4342$

$1.01(0.91,1.11) \quad 0.8773$

Reference

$1.08(0.99,1.19) \quad 0.0979$

$1.05(0.96,1.14) \quad 0.3263$

$1.05(0.96,1.14) \quad 0.2666$

$0.69(0.21,2.28) \quad 0.5484$

$0.96(0.83,1.11) \quad 0.5745$

NOS, not otherwise specified; $\mathrm{HR}$, hazard ratio; $\mathrm{Cl}$, confidence interval. 
Table S5 Univariable Cox regression analysis for cancer-specific survival in patients with gastric cancer

\begin{tabular}{lcc}
\hline Variables & HR $(95 \% \mathrm{Cl})$ & $\mathrm{P}$ value \\
\hline Primary site & Reference & \\
Cardia & $0.99(0.94,1.05)$ & 0.7774 \\
Oxyntic mucosa & $1.05(1.00,1.11)$ & 0.0493 \\
Antral mucosa & $1.42(1.32,1.53)$ & $<0.0001$ \\
Stomach, NOS & $1.72(1.59,1.85)$ & $<0.0001$ \\
Overlapping lesions & & \\
\hline
\end{tabular}

NOS, not otherwise specified; HR, hazard ratio; Cl, confidence interval.

Table S6 Multivariable Cox regression models evaluating the association between Lauren's classification and cancer-specific survival

\begin{tabular}{|c|c|c|c|c|c|c|}
\hline $\begin{array}{l}\text { Lauren's } \\
\text { classification }\end{array}$ & \multicolumn{2}{|c|}{ Crude } & \multicolumn{2}{|c|}{ Model III } & \multicolumn{2}{|c|}{ Model IV } \\
\hline Intestinal & Reference & & Reference & & Reference & \\
\hline Diffuse & $1.44(1.38,1.50)$ & $<0.001$ & $1.19(1.13,1.24)$ & $<0.001$ & $1.20(1.15,1.26)$ & $<0.001$ \\
\hline
\end{tabular}

Adjustment III: age; primary site (5 sites); grade; T stage; N stage; M stage; tumor size. Adjustment IV: age; sex; year; primary site (5 sites); grade; T stage; N stage; M stage; operation; chemotherapy; tumor size; race; insurance; marital status. NOS, not otherwise specified; HR, hazard ratio; $\mathrm{Cl}$, confidence interval. 